\title{
Synchronicity and Sensation: the causal theory of Lady Mary Shepherd
}

\author{
by
}

\author{
Amanda MacIsaac
}

A thesis submitted to the Faculty of Graduate and Postdoctoral Affairs in partial fulfillment of the requirements for the degree of

Master of Arts

in

Philosophy

Carleton University

Ottawa, Ontario

(C) 2013, Amanda MacIsaac 
Library and Archives

Canada

Published Heritage

Branch

395 Wellington Street

Ottawa ON K1A ON4

Canada
Bibliothèque et

Archives Canada

Direction du

Patrimoine de l'édition

395 , rue Wellington

Ottawa ON K1A ON4

Canada
Your file Votre référence

ISBN: 978-0-494-94588-9

Our file Notre référence

ISBN: $978-0-494-94588-9$
NOTICE:

The author has granted a nonexclusive license allowing Library and Archives Canada to reproduce, publish, archive, preserve, conserve, communicate to the public by telecommunication or on the Internet, loan, distrbute and sell theses worldwide, for commercial or noncommercial purposes, in microform, paper, electronic and/or any other formats.

The author retains copyright ownership and moral rights in this thesis. Neither the thesis nor substantial extracts from it may be printed or otherwise reproduced without the author's permission.
AVIS:

L'auteur a accordé une licence non exclusive permettant à la Bibliothèque et Archives Canada de reproduire, publier, archiver, sauvegarder, conserver, transmettre au public par télécommunication ou par l'Internet, prêter, distribuer et vendre des thèses partout dans le monde, à des fins commerciales ou autres, sur support microforme, papier, électronique et/ou autres formats.

L'auteur conserve la propriété du droit d'auteur et des droits moraux qui protege cette thèse. $\mathrm{Ni}$ la thèse ni des extraits substantiels de celle-ci ne doivent être imprimés ou autrement reproduits sans son autorisation.
In compliance with the Canadian Privacy Act some supporting forms may have been removed from this thesis.

While these forms may be included in the document page count, their removal does not represent any loss of content from the thesis.
Conformément à la loi canadienne sur la protection de la vie privée, quelques formulaires secondaires ont été enlevés de cette thèse.

Bien que ces formulaires aient inclus dans la pagination, il n'y aura aucun contenu manquant. 


\begin{abstract}
The theory of causality proposed by Lady Mary Shepherd takes shape over a series of essays that were developed as direct responses to the major competing theories of her day. This paper is an exposition of the Shepherd's Causal theory, and the principles and definitions regarding objects, ideas, objects acting as cause, necessary connection, the content of sensation, and the epistemic justification for causal belief, with the intent of rebuilding her theory and preparing it for a modern audience. Like other empiricists, Shepherd believes experience is central to knowledge formation, and an external world informs this experience. Challenging sequential accounts of causation Shepherd proposes that cause and effect are synchronous. By examining how Shepherd criticizes other theories, and with the help of modern treatments of her work, it will become clear that her metaphysics and epistemology necessitate cause and effect relating in this way in order to justify causal belief.
\end{abstract}




\section{Acknowledgements}

In any project of this size there is always a body of people who come together and form a community around any given philosopher, this paper was no exception. This list cannot hope to encompass everyone who has played a part in my research, and those whom I have missed I apologize and thank you for everything. Of those I can name, I would like to thank Assistant Professor Melissa Frankel, first and foremost, for her invaluable help as an educator and my advisor throughout this process. I would also like to thank Associate Professor David Matheson, whose intrigue in Shepherd's metaphysical and epistemological claims elevated my own, and for his help working through arguments. As well, I would like to thank my fellow Graduate Students in the department of Philosophy here at Carleton. Their interest in and conversations about the topics herein helped to shape the direction of my research and assure me of the value of this project. I would also like to thank Associate Professor Julie Murray for her edits and curiosity about the moral implications of Shepherd's theory. Professor Jay Drydyk, Graduate Supervisor, and Sandra Kirkpatrick, Department Administrator, both of whom provided me with invaluable administrative and technical support should not go without acknowledgement for their fine work and patience with my constant questions. My thanks as well extend to Ellie for reading my drafts and providing invaluable feedback. Craig Underhill has also been an undeniable source of strength and motivation from the beginning, without his faith in my knowledge and purpose I would not be where I am today. And finally I would like to thank Professor Geraldine Finn, who showed me just how important it is to return voice to our philosophical grandmothers. 


\section{Table of Contents}

Abstract .........................................................................................................................................................ii

Acknowledgements........................................................................................................................................iii

Table of Contents ........................................................................................................................................ iv

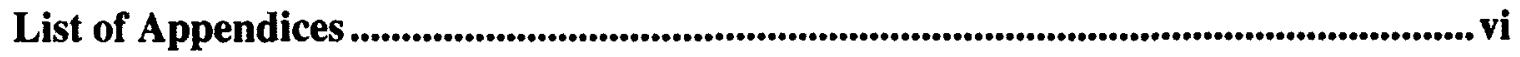

1 Chapter: The Metaphysics of Objects................................................................................... 1

1.1 The Importance of Reading Lady Mary Shepherd .............................................. 1

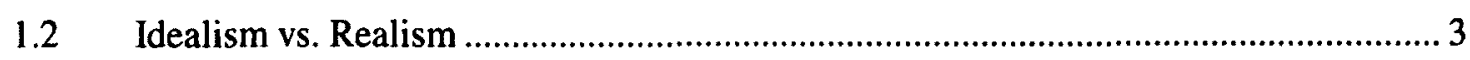

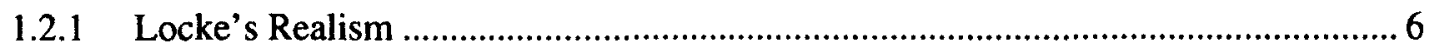

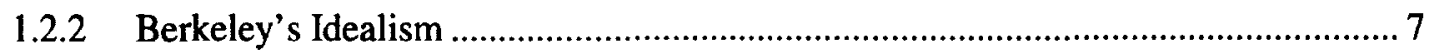

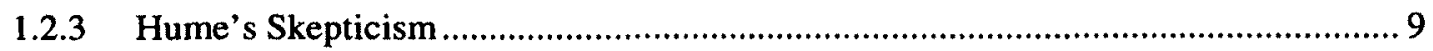

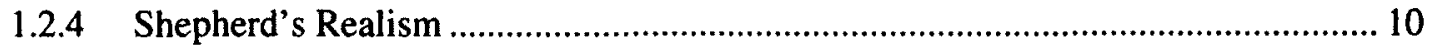

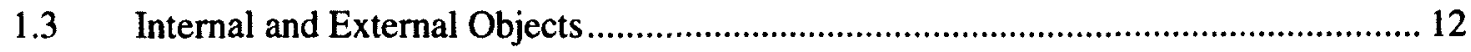

$1.4 \quad$ The Characteristics of External Objects.......................................................... 14

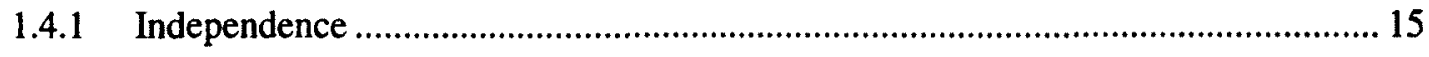

1.4.1.1 Addressing the Challenge of Dreams and Insanity .................................... 19

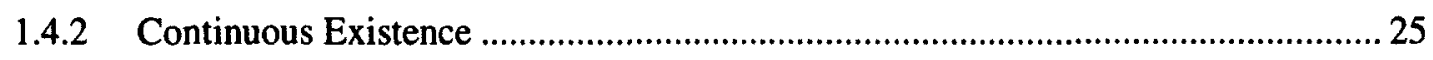

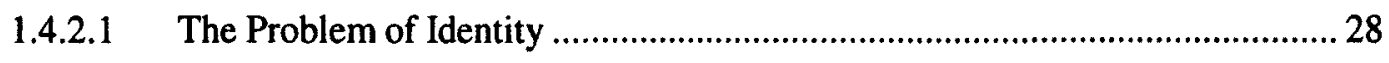

1.5 Internal Objects and their Relation to the External World ..................................... 32

1.6 Linking External and Internal Objects through Causality ....................................... 37

2 Chapter: Shepherd's Theory of Causation.......................................................................38

$2.1 \quad$ Framing Shepherd's Theory of Synchronicity ......................................................... 38

2.2 Malebranche, Hume and Brown: Three theories of necessary connection ................. 40

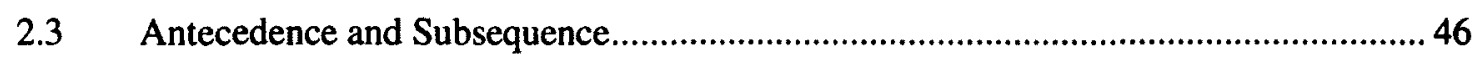




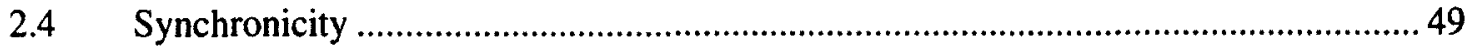

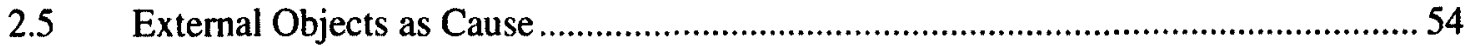

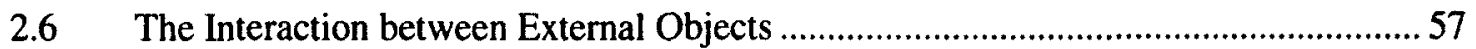

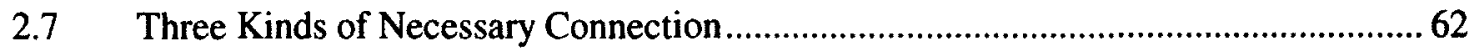

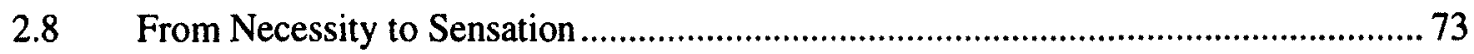

3 Chapter: The Faculty of Sensation ...................................................................................75

3.1 Sensation, Perception, and the Search for Epistemic Justification of Belief................ 75

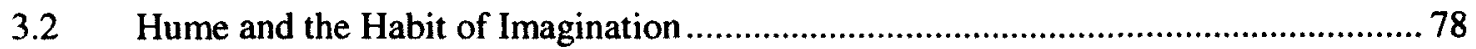

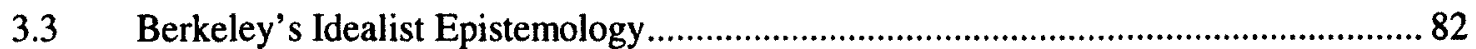

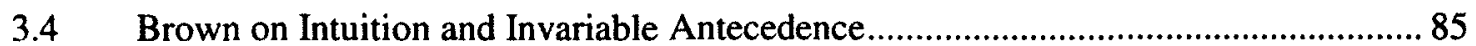

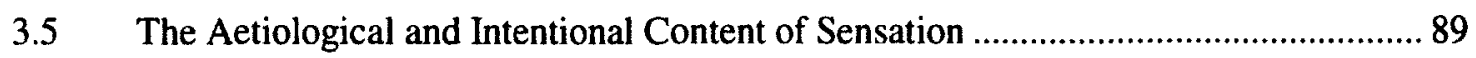

S.6 Shepherd's Epistemic Justification for Causal Belief ........................................ 95

3.7 Challenging Framework Models of Perception................................................... 102

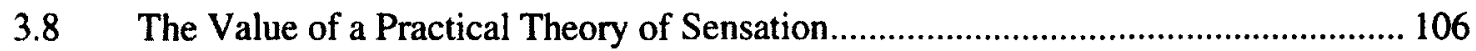

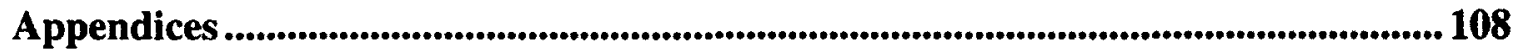

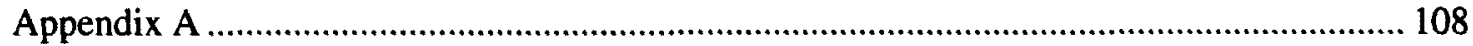

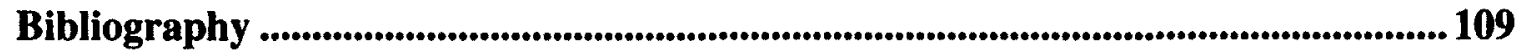




\section{List of Appendices}

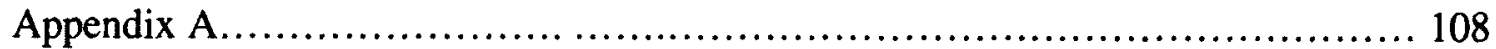

Additional bibliographical and biographical resources related to Lady Mary

Shepherd 


\section{Chapter: The Metaphysics of Objects}

\subsection{The Importance of Reading Lady Mary Shepherd}

Lady Mary Shepherd is a relatively obscure philosopher, but over the past twenty years she has begun to regain the attention of the modern philosophical community. Publishing in the early 1800 's, she was an active member of the Scottish philosophical community and produced several essays, short papers, and correspondences with fellow philosophers such as John Fearn. Her work primarily focuses on establishing definitions and principles for a new causal theory. Much of this work is done in response to the causal theories made popular at the time by philosophers such as Dugald Stewart, and as such her own theory is formed over the entire body of her essays in the form of critiques against the prevailing theories, rather than in a single opus dedicated to its explanation. Several of these critiques are aimed against Bishop Berkeley, Dr. Hume, and Dr. Thomas Brown, figureheads within the Scottish Enlightenment that started a century before her. Other pieces address more peripheral philosophers, such as Reid and Fearn, but who were equally important for their participation and influence in Edinburgh during the time Shepherd was educated and beginning to publish.

While at first glance, Shepherd seems to be an anomaly among women of her day, recent reclamation projects by feminist philosophers have uncovered a growing number of women, throughout history, who were actively engaged in philosophy and often well respected by their peers. Shepherd marks a class of women who had access to education and texts, whether or not this was done formally through an institution, and was for the most part well respected by her peers. Robert Blakey spoke well of her philosophical 
views in the $9^{\text {th }}$ volume of $A$ History of Philosophy of Mind published in 1850, just three years after she died in $1847 .{ }^{1}$

The value in assessing the works of a philosopher like Lady Mary Shepherd is found both in the grander project of reclamation engaged in by these feminist philosophers, as well as in a fresh evaluation of the "marketplace of ideas". Shepherd was well read, and was herself read widely, with publications in scientific journals, such as Parriana and Fraser's Magazine, and with her essays used as educational texts in the University of Edinburgh. Her engagement and acceptance by the community indicate that they saw value in her philosophical ideas, and this alone makes her worthy of a reevaluation under a modern lens. Her work evaluates and challenges the ideas presented by many well known philosophers, philosophers who have become the foundation of modern philosophical education, in history of philosophy as well as other active branches of philosophy, such as metaphysics and epistemology. If Shepherd has something valuable to add to this conversation, it will only be discovered by taking a more serious look at her critical work regarding these philosophers and her original work in the formulation of a new theory of causality.

The aim of this paper will be to start such an evaluation. Since Shepherd's theory is formed piecemeal over the span of her writings, and generally as responses to other philosophers, the important evaluative work will consist in framing Shepherd within a specific philosophical context or question, and juxtaposing her theories to those presented by the philosopher's she addresses. Margaret Atherton and Martha Brandt Bolton, two

\footnotetext{
1 Much of this biographical information can be found in the introduction of The Philosophical Works of Lady Mary Shepherd (2000), edited by Jennifer McRobert. McRobert cites several sources, including Blakey's A History of the Philosophy of Mind and Shepherd's daughter's memoir. Further information on these resources can be found in the appendix.
} 
modern philosophers who have published about Shepherd's life and philosophy, offer other important contextual and evaluative work that will be used to aid my own inquiry. Bolton, in particular, provides an account of Shepherd's epistemological search for justification in causal belief, which is both informative about how to interpret Shepherd in a modern epistemological framework, and provides an excellent comparative evaluation of Shepherd's and Hume's differing opinions regarding causation and sensation.

The focus of this first chapter will be uncovering and explaining Shepherd's definitions and principles regarding objects. It will address the nature of Shepherd's realism, the different kinds of objects she proposes, and what is metaphysically required for something to be considered as one kind of object over another. The second chapter is still concerned with the metaphysics of objects, but more specifically with how and when objects can act as causes, and the underlying principles of causality, namely necessary connection, and Shepherd's proposed synchronicity of causes and effects. Finally, the third chapter will address the questions of how we achieve knowledge of these causal principles why we are justified in forming these beliefs. It is my hope that over the course of this exposition, Shepherd's theory will be found to be philosophically viable, but this wish is second to the importance of simply establishing an account of her causal theory for future and more detailed evaluation.

\subsection{Idealism vs. Realism}

Causality and necessary connection are the primary focus of Shepherd's critical work, but in order to be able to properly explore these ideas, a sufficient background in the foundational concepts Shepherd proposes must be developed, namely those 
surrounding objects. Shepherd has a unique understanding of objects, proposing that there are essentially two kinds, internal and external objects. Internal objects have an idealistic character to them, but external objects propose an external reality in opposition to these ideal objects. Knowing a bit more about the realism-idealism debate that was ever present between early modern Empiricists will give us a better idea of where Shepherd fits within this debate. The division of objects is just the starting point for her re-evaluation of contemporary causal theory, but despite its innovative approach, there are still some concerns that arise regarding the characteristics of objects, some of which are perennial questions in philosophy, and some of which are undoubtedly unique to Shepherd's causal theory.

Lady Mary Shepherd published her largest and most comprehensive pieces in the 1820 's, well into the maturity of the Scottish Enlightenment, when many important and foundational members of the Empiricist movement were very popular. Despite their emphasis on an experiential account of metaphysics and epistemology, all of these philosophers had a strong faith logic and reason, and Shepherd was no exception. Her critiques ranged in topic and period from Hume and Berkeley, to Thomas Brown and even foreigners like Kant. To build her metaphysics she offered critiques of these philosophies along with variations and solutions to them. At the core of this critical work however, was the exposition and elaboration of her own metaphysical and epistemological theory which was grounded in a deep sense of realism and a unique view of human rationality.

Her metaphysical theory is perhaps best characterized by her separation of objects into two categories, internal and external objects; this division, and the relation that these 
objects share is something that echoes throughout her other metaphysical and epistemological theories. In traditional realist accounts of objects philosophers are typically divided into two schools of thought, substance dualism or strict materialism. All realists agree that there are at least some physical objects which are independent of human experience. Metaphysically, physical objects exist independently of the mind; epistemologically, they provide a posteriori justification for our belief in certain truths. In contrast, idealists hold that physical objects do not exist independently of the mind. These mind-dependant objects can still act as a posteriori justification for belief, but their dependence drastically alters their metaphysical character. Idealists, more often than realists, face the challenge of solipsism, because mind dependent objects pose a direct challenge both to the ability to account for minds other than our own, and for notions of identity, since it is possible that even our identity is the product of some other mind. Realists, on the other hand, must answer to the challenge of skepticism in the face of human fallibility. This skepticism arises when the errors in human perception raise questions about the justification for human belief. If we cannot reliably account for the physical source of some of our perceptions, during dreams or insanity for example, then their reliability during "normal" circumstances can be called into question.

Although she styles herself a realist, Shepherd does not fit easily within either category with a cursory considering her metaphysical classification of objects. She divides objects into two types: External objects are real objects existing independently of human minds, while internal objects are mind-dependent existences. In order to get a better understanding of how she fits into the Realist-Idealist debate, let us take a brief look at three of the philosophers she distinguished herself against, Locke, Berkeley, and 
Hume. Each of these philosophers is a representative of Realism, Idealism, and Skepticism respectively, and seeing where Shepherd's philosophy stands in comparison to them should allow us to determine how she fits into the metaphysical debate.

\subsubsection{Locke's Realism}

Locke, often considered the first empiricist, believes that all of our ideas come from two sources, either the perception of outward physical objects or our reflection on the operations of our own minds. He explains that, "external objects furnish the mind with the ideas of sensible qualities, which are all those different from perceptions they produce in us: and the mind furnishes the understanding with ideas of its own operations," (Locke, 78-79). Combined, these two sources provide us with all of our ideas, but physical objects are the genuine causes of our ideas of sense. Locke explains that these outward objects are extrinsic to the mind and in combination with our ideas of our own internal thought processes, form the basis of all of our knowledge (Locke, 89).

Primarily he develops this view in contrast to the idealist/rationalist conception of innate ideas. If such a priori concepts were possible, they could provide a basis for our knowledge without needing experience, and we would be able to create the sum of human knowledge through reason alone. Though this is primarily an epistemological concern, it brings into question whether we need to make reference to an external world at all. With the existence of innate ideas, the relevance of an external world becomes diminished since all knowledge could be reached through the use of reason and innate ideas alone.

Locke agrees that there are some things we come to know through the use of reason, but this is not itself a proof of innate ideas. Even should the whole of humanity 
agree upon some principle, this assent would not be proof that the principle was innate. In fact, assent can only be arrived at after we have reasoned through an argument that such a principle is the case, and thus could not be innate, or we would have simply be able to accept them as truth without subjecting them to consideration (Locke, 22-24).

Since innate ideas are not the foundation of knowledge, external objects take up this role. For Locke these objects are actually existing objects that express qualities to the mind. He states that,

Whatsoever the mind perceives in itself, or is the immediate object of perception, thought, or understanding, that I call idea; and the power to produce any idea in our mind, I call quality of the subject wherein that power is...Qualities thus considered in bodies are: first, such as are utterly inseparable from the body, in what state soever it be...

(Locke, 104)

These qualities inhere in their objects, that is, they are utterly dependent on their objects

for their existence. Primary qualities, things such as solidity, extension, motion and number, are those qualities which are essential to an object; they cannot be removed from it by any means (Locke, 104). Secondary qualities are not essential to objects themselves, but are those qualities which work to excite ideas of sense in us, such as colour, taste, smell, and so on (Locke, 104-105). These qualities can be removed from an object and it will still retain something essential about itself.

\subsubsection{Berkeley's Idealism}

Berkeley believes that physical objects cannot account for the creation of ideas in our minds, because physical objects can only interact with other physical objects, while mental objects (or ideas) are the only kinds of objects which can affect other mental objects. Like Locke, ideas come from a few select sources, either ideas are imprinted on the senses, perceived by reflection on the passions, or formed with the aid of memory and 
imagination (Berkeley, 24). All of our ideas about external objects share in common the fact that we perceive them. For Berkeley, all objects of sense are really just ideas. None of these objects is capable of existing independently of the mind because ideas inherently rely on minds for their existence (Berkeley, 25). This is backed up by the notion that "only like can cause like", in which he argues that only physical bodies can affect physical bodies, likewise with spirits and minds. Accordingly, all of our ideas must in turn be caused by ideas, and since perceptions are ideas, the objects which cause them must too be ideas. Physical objects are thus ideal, that is they are constituted of ideas, and dependent upon minds for their existence, but they are nonetheless real in that they exist independent of humans in particular and are not a complete fiction of our own minds (Berkeley, 35-37).

Human minds lack the power to create and maintain the whole of reality. There are facets of our experience, namely the regularity of experience and the continuity between periods of absence (sleeping, leaving a room, etc.), that require something independent of our experience to account for them. Ideas can only exist in the mind, yet our ideas of objects contain notions of persistence after going unobserved. If Berkeley is to maintain that this idea of continuance is true, he must account for the existence of these ideas independent of human experience in particular. Thus he proposes that there must be some ultimate perceiver in whom these ideas can continue perceived even though a human mind is absent (Berkeley, 148-168). Since God is omniscient all ideas have an eternally existing perceiver to account for their continued existence, and we do not need to worry that we are simply conjuring or fabricating the world every time we open our eyes. 


\subsubsection{Hume's Skepticism}

There is some debate as to whether Hume can truly be considered a skeptic. For the purposes of presenting the third position in the realism-idealism debate I will consider him as one. Considered as a skeptic, Hume has little faith in the reliability of our senses, and understandably he questions the surety with which we can make accurate claims about an external world. Because the senses are the means by which we interact with the world their reliability has a direct impact on the things we can accurately claim about it. External objects, if they exist independently of the mind, can only be known with a small amount of certainty since it is easy to fool the senses. This fallibility is evident when considering dreams, illusions, and states of insanity. In these conditions we sense a whole variety of things which cannot rationally be accounted for. For example we may dream that apples fall up into the sky, or that coldness causes fire. We sense these things as vividly as if they were real and so our sensations under normal conditions must be called into question.

If, on the other hand, objects depend on the mind, the problem is compounded. Not only are we forced to question whether our sensations are reliable on the same grounds as before, this also calls our rationality into question. If our judgments are based upon, or deal with our sensations, how can we be said to make accurate judgments about any idea, even those that pertain to our own minds or existence.

Ultimately, it is only through custom or habit, that we gain a semblance of knowledge. In typical conditions we come to recognize that "the idea of necessary connexion among events arises from a number of similar instances which occur of the constant conjunction of these events," (Hume 1998, 114) but we also recognize that any 
one of these events alone would never be enough to grant us this knowledge, even after a thorough examination. To claim that such an idea is caused by an external object requires years of experience to corroborate. There is very little of the nature of sensations themselves that would grant us the idea of this externality, but there is equally little evidence to support that the causes of our sensations are ideas alone. Thus for Hume, the source of our sensations and perceptions is of little consequence, because neither can give us a true picture of the world and both are prone to human error. Practically, the belief in real physical objects is more useful to us, but we must still remain skeptical of claims regarding causal knowledge, because its sources are suspect and its connections tenuous at best.

\subsubsection{Shepherd's Realism}

Having seen three clear examples of different sides of the realism-idealism debate, placing Shepherd should be a little simpler. Unavoidably, she does not fit easily within the realist category because of how she understands objects as two kinds. She states that,

there are two sets of OBJECTS in nature; viz. the EXTERIOR OBJECTS, the acting causes of nature, independent of the senses; the INTERNAL OBJECTS, the sensible effects of these, when meeting with the human senses, and determining their specific qualities upon the mind.

(PWMS 2.XIV ${ }^{2}$ )

Shepherd proposes that there are really existing objects which make up the external world. We can know of their existence through our sensations and rational inquiry, but we are currently incapable of knowing much about their true nature. She compares these

\footnotetext{
2 This refers to The Printed Works of Lady Mary Shepherd (2000) by Jennifer McRobert, and is a naming convention adopted from Martha Brandt Bolton in her 2011 article "Causality and Causal Induction: The Necessitarian Theory of Lady Mary Shepherd". 1.n refers to a selection from volume 1 and $2 . n$ refers to volume 2.
} 
external objects to Hume's secret powers in nature, and believes that they are the only things capable of acting as true causes. Like Locke's external objects, they are the sources of our perceptions.

Atherton explains that despite difficulty placing her, "Shepherd is committed to realism with respect to the causes of our ideas, but unlike the Scottish realists, like Reid and Stewart, she does not suppose that we are in a position to give content to any account of these causes,"(Atherton 2005, 76). While this is true when dealing with particulars about causes, Shepherd does believe that our experiences tell us both that external objects exist, and that there are certain general characteristics which these objects exhibit, namely that they exist in space and time, relate to one another and to effects, and are the only objects which can act as causes. Equated with both sensations and effects, internal objects display a very similar character to Berkeley's ideal objects, they exist only in the mind. External objects on the other hand, are real and mind-independent; they absolutely do exist and act as causes. Shepherd believes that internal objects are representative of the external objects that cause them, although as Atherton points out, they cannot give us any specific information about any particular external object. When our senses work in combination with the faculty of reason we are able to formulate true knowledge about the existence of external objects and the relationships between them and internal objects. So, while our first hand experience of the world is constructed idealistically, the real existence of the world itself can be attested to and is referenced by these internal objects.

Shepherd clearly isn't a skeptic regarding external existences, but neither does she believe they are the only sorts of objects. In her 1994 book Women Philosophers in the Early Modern Period, Atherton explains that, 
She seeks to escape Hume's skepticism by showing that we have within our mental powers, specifically within our reason, the capacity to arrive at such knowledge. What she makes it her business to show is that it is rational to believe that events have causes, that like causes have like effects, and that our sensations could not be explained unless external bodies existed.

(Atherton 1994, 148) Despite the ideal character of internal objects, not only do they depend on the mind, but they depend on external objects for their existence. This dependence on external objects can be accounted for because of how sensation works. Sensation for Shepherd is a combination of the information we receive from the external world with the rational judgements we form about this information. This co-operation will be discussed in more detail later when looking at sensation specifically, but for now it is important to realize that sensation is not passive, nor solely informed by the external world, nor capable of acting independently of external input. Sensation is an action that must necessarily combine externally provided information with the rational judgements we make about that information. This houses Shepherd safely within the realm of Realism, while at the same time allowing her the flexibility necessary to account for the subjective aspects of experience. This flexibility forms a theory of causality which is stricter in how it allocates causal roles and the relations between both kinds of objects as compared to other accounts of causality. But at the same time it is a more general theory in that it deals with the general principles of causation rather than the specifics of individual instantiations of causal relationships.

\subsection{Internal and External Objects}

Now that we have a little bit of a background and can safely say that Shepherd is a realist, albeit of a sophisticated sort, we can start unpacking her concept of objects. The foundation of Shepherd's metaphysics rests on her classification of objects into their two 
kinds. The distinction between internal and external objects will form the basis for their relationship of necessity. The relationship between these objects is causal at its core. Shepherd believes that if we properly understand this relationship we will see that experience can grant us accurate knowledge about the world. In response to Humean skepticism, she argues that our sensations, in concert with our ability to use reason to reach principles of causal necessity, form the basis of all our knowledge, as opposed to habit alone. But before we can get at the epistemic justification for our belief in an external world, Shepherd must set out the metaphysical principles she intends to support.

She classifies objects under two distinct categories; first there are external objects, which exist independently of the mind and are the source of our perception. These are juxtaposed to internal objects, which are the objects of sense. These objects are dependent on the mind, and are caused by external objects (PWMS 2.XIV, 2.40-42). Internal objects are intended as an augmented version of the common use of the term 'objects'. Internal objects can be described as the collections of sensible qualities that form the impression of a singular entity external to us. That is, internal objects are the sensations caused by external objects and the ideas that these sensations form within the mind. This distinction may seem trivial at first, since internal objects are merely the subjective experience of external object. However, this differentiation forms the cornerstone of her arguments surrounding causation because it clearly defines the sorts of things which have the power to act as causes and which things must be effects. The category of external objects overlaps with that of causes and on occasion effects, while internal objects overlap with sensations and effects exclusively. 
This basic principle will be what allows Shepherd to distinguish her theory from her contemporaries, as it develops into a unique interpretation of causal necessity, causal interaction, and the process of sensation that could not be reached otherwise. The first steps to understanding the kind of causality that Shepherd is proposing is looking at the characteristics which define external objects and understanding why these sorts of objects are very different from the kinds of objects that are to be considered as sensible effects.

\subsection{The Characteristics of External Objects}

As part of her explication of objects in general, Shepherd also differentiates between inward and outward existences. This is a slightly different approach to the distinction between internal and external objects, but it affords us a broader view of the character of external objects. She explains that,

Inward existence is the capacity for sensation in general; outward existence is the exciting cause for some sensation in particular. The one is the very mind itself, or the power of thought and feeling; the other is a motive, or cause for a particular kind of it, and therefore out of, and distinct from, the continually existing essence of [the mind]. That is inward existence, of which the individual is only conscious; that is outward, which is in relation to the organs of sense, and to motion, in order to be apprehended, and must be met by them before it becomes inward...

(PWMS 2.41)

This distinction serves a dual purpose. First, it is meant to highlight the difference between what can be considered inward and outward existence. This loosely transposes over the discussion of objects and effects, however, under the framework of 'existences' this takes on an "event-like" consideration. While external objects are causes to internal objects, so too are external events causes for internal events. Both the external and internal counterparts of causation exist in relation to each other and to the mind. Acts of causation are phenomena, meaning that external objects act as causes to the internal objects only when they engage in a relation with the senses. Her second goal is to provide 
evidence for the external nature of 'outward' objects. Shepherd is attempting to clarify the distinction between processes of the mind and external sources of sensation, while also providing experiential reasoning for why these sources must exist external to the mind. Inward existence is not merely our sensations or ideas about sensations; it is all the processes of the mind that can operate without the continued presence of physical objects or sensory input. This is the first of several key characteristics which serve to define the limits of external objects. Along with this external nature, external objects must express independence and continuity. These two characteristics, while being formulated in response to Berkeley's idealism and Hume's skepticism also present their own inherent challenges -namely of the problem presented by dreams and the problem of identity-and Shepherd must provide an answer to these in order to warrant the principles she proposes.

\subsubsection{Independence}

Independence is of great importance to Shepherd's separation of objects. It sets external objects apart from sensations and allows them to exist outside of our minds without our personal need to account for their existence. This is in contrast to Berkeley's ideal objects, which must depend on the Divine Perceiver so that their externality to human minds can be accounted for. Shepherd on the other hand, does not believe that ideas of sense are caused by other ideas, at least not in the manner Berkeley conceives.

Berkeley states that,

neither our thoughts, nor passions, nor ideas formed by the imaginations, exist without the mind, is what everyone will allow. And it seems no less evident that the various sensations or ideas imprinted upon the sense, however blended or combined together (that is whatever object they compose) cannot exist otherwise than in a mind perceiving them.

(Berkeley, 25)

Shepherd replies that, 
Bishop Berkeley is guilty of an ambiguity, when he speaks "of ideas being imprinted on the senses," "of our perceiving" (by sense) "our own ideas and sensations," for he appears to speak of the "senses on which objects are imprinted," as if he intended by them those five organs of sense, viz. the eye, the ear, \&c. vulgarly called the senses, but which, in truth, have no sense or feeling in themselves as independent of the mind ; but are mechanical instruments ; which as powers modify exterior existences, ere they reach the sentient capacity ; the which capacity as a general power or feeling becomes modified thereby ; for undoubtedly, the senses as organs cannot perceive what the senses as organs are required to form... The ideas of colours cannot be imprinted on the eye ; not those of sound on the ear ; nor those of extension on the touch; for there are no such IDEAS, until after the eye, as an instrument, has been affected by some sorts of outward objects, fitted to convey to the sentient principle, a sensation of colour, and so the rest. Therefore the objects perceived by the organs of sense cannot be our ideas, and sensations.

(PWMS 2.198-200)

The equivocation Shepherd speaks of is between the ability of the senses to form our ideas of sense, and their supposed ability to allow us to perceive our own ideas. ${ }^{3}$

Shepherd is arguing that the organs of sense are very different from our faculty of sensation. She believes that we can indeed use this faculty to 'perceive' our own ideas and sensations, but the organs of sense themselves have no ideas, they are merely the tools with which we are able to interact with the world. Nor do the ideas exist outside of the organs of sense in such a way that they can be stamped upon them, the organs of sense cannot themselves 'sense' what they are instrumental in creating. Rather, the ideas we form of sense, our sensations, are formed by the interaction of these tools and the external world. Two important conclusions can be drawn from this: first, that our sensations get their material from something that exists independently and second, that the mind is also capable of acting as one of these independent sources.

\footnotetext{
${ }^{3}$ Atherton, in her 1996 paper 'Lady Mary Shepherd's Case Against George Berkeley", accuses Shepherd of failing to grasp the real claim that Berkeley is making about the organs of sense, which is not about the conscious use of the eye, but rather that the eye or any other sense organ is made of a collection of related sensible qualities (Atherton, 359). This accusation may be correct, but it does not diminish the claims that Shepherd is making against such accounts of sensation, even if Berkeley is not beholden to these notions.
} 
Both Shepherd and Berkeley agree that ideas are dependent on minds for their existence. They also both agree that minds can act as causes. This is most evident when our internal states are affected by previous states, such as our anger clouding our judgment, or a fear prompting a reaction.

Though Shepherd believes sensation is an active capacity of the understanding, it does not and cannot have any creative or causal power because it is just a collection of the impressions caused by external objects. Her critique of Berkeley here is intended to be a clarification of the process of perception. We do not perceive our sensations, rather we perceive external objects. These objects exist in the world and act upon our organs of sense; these organs act as a bridge between external objects and our faculty of sensation and create our sensations. The collection of these sensations into recognizable objects is what we traditionally class as the act of sensing or perceiving and the resulting collections are the internal objects Shepherd describes earlier.

When we sense our own mind, when the mind reflexively forms the idea of itself, our faculty of sensation is recognizing yet another external object. A mind can then be considered as an object which is able to express qualities called ideas. External objects, then, do not always have to be physical, as their name might suggest. The mind differs from other external objects only in that it can express consciousness, memory, and imagination to the senses. Since all qualities depend on their objects for their existence, ideas, which include ideas of sensations, depend on the mind for their existence. What guarantees the independence of other objects from both the senses and the mind is their externality to sensation and our immediate recognition that they are also distinct from the mind. 
It is not enough to claim that objects exist independently of the senses; they must also be external to them. If we claim that something is internal to the senses but independent of it, this would be the same as claiming that our senses contain something which is not a sensation. Shepherd would find this problematic for the same reasons she believes Berkeley is incorrect for associating ideas with the organs of sense. Likewise if we were to believe that something could exist externally but not independently we ought to be able to manipulate these things at will with our mere thoughts. Berkeley initially claims externality but not complete independence; as ideas, objects must depend on some mind for their existence. This answers why humans cannot completely fabricate the world by their own volition. However, Shepherd argues that this is still inconsistent, because even though they are external to human minds, they are not ultimately external to the mind of the Divine Perceiver. She is not challenging the idea of a divine mind with this complaint, rather she is pointing out how Berkeley's ideal objects, through their inherent dependence on something external to themselves, are relieved of their causal power. The objects he describes are akin to the internal objects of Shepherd's metaphysics, but they cannot be considered the causal objects upon which these internal objects necessarily depend. She explains that,

It is not enough that the causes for sensation in general, CONTINUE to exist and to be INDEPENDENT of the PARTICULAR causes which excite PARTICULAR notions; because these latter might nevertheless be DEPENDANT on them; and this is the case in dreams: But the particular exciting CAUSES, for particular sensations (termed the perception of qualities,) must prove themselves capable of CONTINUING to exist, INDEPENDENT of the other powers of sensation in general.

(PWMS 2.89)

This independence cannot be just in a particular case, as in saying that the apple is independent of the sensation it causes. All causes must be independent of all sensations in 
general. This means that a sensation or a sensible effect cannot become a cause at any point, which has interesting implications for sequential accounts of causation which typically see old effects become the new cause in a causal chain. We can already start to see that Shepherd will not be taking the traditional sequentialist view of causation such as Brown's, which supposes the primary characteristic of causation is the antecedence of causes and subsequence of effects. Not taking this stance, it is important for her to establish strong definitions of objects and their roles, in order to properly defend her choice to abandon this convention.

Even with the concept of independence well defined, Shepherd must still answer to the challenge presented by dreams and insanity, which is a significant issue faced by all realists. Dreams and insanity present a set of unusual circumstances under which we can question the reliability of our senses and reason to form accurate judgments about the world, and which as a result lead us to question the accuracy of the senses and reason even under ideal conditions.

\subsubsection{Addressing the Challenge of Dreams and Insanity}

If we consent, for the time being, that during waking and sane states we are sufficiently convinced of the existence of an external world, insanity and dreams still present a real problem for our ability to place any trust in the accuracy of our sensations and thoughts even during normal operation. For Berkeley, the vivacity of dreams and corrupted mental states are used as arguments against the experiential justification of belief in existence of external independent objects, yet Shepherd believes that these arguments provide insufficient evidence to dissuade us from our belief in such objects. 
In Sections 18 to 20 of the Principles, Berkeley explains that while we are

dreaming or suffering a bout of insanity we are fully immersed in that illusion and

believe in the external nature of the objects we perceive in those states. He explains that,

I say it is granted on all hands (and what happens in dreams, phrensies, and the like, puts it beyond dispute) that it is possible we might be affected with all the ideas we have now, though no bodies existed without, resembling them. Hence it is evident the supposition of external bodies is not necessary for the producing our ideas: since they are produced sometimes, and might possibly be produced always in the same order we see them in at present, without their concurrence...Suppose what no one can deny possible, an intelligence, without the help of external bodies, to be affected with the same train of sensations or ideas that you are, imprinted in the same order and with like vividness in his mind. I ask whether that intelligence hath not all the reason to believe the existence of corporeal substances, represented by his ideas, and exciting them in his mind, that you can possible have for believing the same thing?

(Berkeley, 31-32)

Accordingly, the production of sensations in the mind cannot give us a good enough reason to suppose that external objects actually exist.

When we return to sanity and reflect upon these experiences we know the objects we experienced depend on the mind, either as ideas inhering in it, or sensations modified by it. If someone can be so completely deluded about the reality of the world during these experiences it seems equally possible that they are also being deluded or deceived during their waking or sane experiences. Shepherd must respond to this challenge in order to maintain the metaphysical responsibility of internal objects to adequately represent external objects. There are two responses she makes to this problem: the first addresses the ability of dream objects to fulfill their definitions and how this affects us in dreaming and waking states. The second addresses ability for any object to be the subject of shared experience.

First, Shepherd replies, in sane and waking states we realize that dream thoughts were delusions because we recognize that during those delusional states several relations 
of ideas were inaccessible to us, and that the objects are incapable of being experienced fully. Shepherd argues that,

The reason it is put beyond dispute that there are no external BODIES resembling our ideas in dreams and frenzies, is because what happens in those states of mind, proves there are no CONTINUOUS INDEPENDENT objects, either resembling, or unresembling the then ideas of sensible qualities; and which can therefore be capable of fulfilling their definitions.

(PWMS 2.94)

We can also recognize this to some extent from within the dream. No matter how

delusional someone is, they still have the notion that their sensations are caused by some object. The dream object may contain all of the sensations of the real object, and likewise all of its sensations will have the same restrictions as the sensations of a real object. This restriction is the inability of sensations to be causes. Shepherd agrees with Berkeley and Hume on this point, for all of them sensible qualities are incapable of acting as causes because of their dependence on the mind (PWMS 2.296-297). Shepherd argues that we know that, "Fire will always burn, and bread will always nourish, but, what do we mean by fire, and bread? The sensible qualities of these will neither burn nor nourish," (PWMS 2.298). Sensible qualities are signs of externally existing object, this is as true of dream sensations as real ones, but dream sensations point to very different external objects. The food of dreams is not real food, nor is the fire of dreams real fire. No matter how much food we consume in a dream, nor how long we hold our hand in the fire, the food will never nourish us nor will the fire burn our skin. Even if we have delusions of the pain or surcease offered by each action, a real change is not affected on our bodies. Dream sensations reference the external object of our own minds, and all the ideas and memories contained within, but not the real bread on the table, or the real fire in the hearth.

Shepherd here gives us the caveat that the objects of dreams are not devoid of original 
material from the external world; she fully admits that at some point we have clearly gotten our ideas of these objects from external sources (PWMS 2.94-95), but the significant reference dreams make is to the states of our mind, and our memory of the experience of objects in the past.

Beyond the failure of these dream objects to live up to their definitions, they also cannot account for the intersubjectivity of shared experiences. If an internal object is to have a real referent, its cause must be independent from sensation and our individual minds to account for the object's ability to be perceived simultaneously by more than one mind and remain relatively uninfluenced by our thoughts. Shared experience is a key indicator that there are external independent existences; my experience of an apple may be of a certain kind, but others could not fail to experience the apple also. The states or qualities of my own mind are such that typically only I have the ability to sense them, yet there are still some qualities that others can sense, namely speech, emotions, and ideas as communicated through other mediums. Those ideas and sensations which depend on my mind for their existence cannot be accessed by other people but those which simply must exist in some mind can be shared between people. Dream objects, which seem very real in dreams, do not provide sufficient evidence against the existence of external objects because, when we reflect on them in our waking states we realize that they fall short of fulfilling their definitions and being capable of being experienced by other people. Thus dreams, while they may pose a problem for individual accounts of perception, are no more troublesome than subjective experience in general when it comes to determining the characteristics of external objects. This response allows us to see how dream and waking states differ upon external reflection, but Shepherd must still answer why our utter faith 
in these objects during dreams does not lead us to suspect a fault in our judgment in general.

Shepherd believes that although we do not have access to the nature of external objects, sensations must necessarily be caused by them. Her definitions of internal objects will confirm this characteristic of them and it is prevalent in her extended discussion of dreams and other minds in Chapter 4 of the Essays on the Perception of an External Universe $^{4}$. Another way to account for dreams is by implying that they do actually give reference to an external object. On a basic level we can claim that this object is the mind itself, which we already know is an external object, and its collection of ideas. In a more extended sense, we could argue that the original content of our sensations which formed the memories and ideas which the dreams and insanity draw upon, were themselves ultimately caused by external objects.

The causal process of a dream can be broken down into several steps. First, when we are in a waking state an object causes a sensation, the experience of which is stored in memory. Several such memories are collected by the mind throughout waking experience. When we enter a dream state and the mind will often recall various memories, sometimes even synthesizing them into "new memories" or ideas, what in other words we simply call "dreams". These dreams have the appearance of our waking experience, but despite the creative power of the mind to synthesize ideas these ideas themselves lack the causal power to excite new sensations in us, due to their dependence and internal nature. Under an incorrect accounting of this process, the mind will be seen as the general cause of our sensations, with the various sequences of ideas that compose

\footnotetext{
${ }^{4}$ Hereafter referred to as the Essays, found in the Printed Works of Mary Shepherd, volume 2.
} 
dreams seen as proximate causes. A more accurate account is that our minds are the proximate causes of our dreams, while all of the causes, or external objects, which originally excited our sensations from which the mind synthesized our dreams, are the general causes thereof.

If we believe that the justification for the belief in an external world comes from the inherent relations of causality and necessity between objects and our ability through experience and reason to grasp these concepts, as Shepherd does, we may be able to circumvent the worry caused by dreams and insanity since our ability to perceive the world has no impact on the veracity of these relationships. ${ }^{5}$ Since she is not concerned with answering questions about particular causes and effects, but rather the general principle that underlies all of these relationships, the peculiar events and causal relationships that take place in dreams are inconsequential, because they are still being caused by something external to that which senses them. She is convinced of the effectiveness of her response to Berkeley, and his contention that our experience cannot justify the belief in external object. But whether this is a satisfactory answer to will predominantly depend on how convincing her arguments about the role of sensations and necessary connection are, but in the meantime it does provide her a ground on which to trust the veracity of sensations when we are trying to achieve causal knowledge. ${ }^{6}$

\footnotetext{
${ }^{5}$ By this means, Shepherd is also able to be able to answer to several challenging phenomena, such as miracles and the supposed suspension of effects.

${ }^{6}$ Cartesian doubt on the basis of dreams is very similar to the challenge presented by Berkeley, but it focuses its attention on our experience from within the dream. I believe that Shepherd's reply still can answer to this, but it remains a concern.
} 


\subsubsection{Continuous Existence}

Apart from Berkeley's worry, dreams also provide a valuable starting point for Shepherd's inquiry into the second characteristic of external objects, continuous existence. It is clear from experience, through dreams and sensory deprivation that the mind can operate without the continued imposition of particular external objects. Shepherd believes it is important to prove that these external objects continue to exist whether or not we perceive their sensible qualities. She addresses this issue by taking a look at the causal reasoning we perform when we experience objects. ${ }^{7}$ When we think about external objects, Shepherd argues that, "the mind perceives, that unless they are created purposely, ready to appear, upon each irregular call of the senses, they must CONTINUE to exist, ready to appear to them upon such calls," (PWMS 2.13-14). This perception is the recognition of the intermittent sensation of internal objects. The mind reasons that there must be some cause for these sensations and it knows them as external objects. So it must be the case that either external objects come into existence (or begin to be) every time the mind has renewed experience of their internal objects, or they exist continuously albeit unobserved when the mind does not experience them. Shepherd argues that these objects continue to exist rather than begin to exist, and that careful reflection on these notions will prove their continued existence is a logical necessity.

This is the subject of the discussion of self-causation in her 1824 critique of Hume and Brown, An Essay upon the Relation of Cause and Effect ${ }^{8}$. Here, she argues that self-

\footnotetext{
${ }^{7}$ Shepherd believes that Sensation (perception) cannot be considered separate from reason because of how the faculty of sensation operates to combine the sensible qualities we experience with causal reasoning about the relations between them (PWMS Essay II, 2.220-238). This will be explored more in chapter three.

${ }^{8}$ Hereafter referred to as On Cause and Effect, found in the PWMS volume 1.
} 
causation is logically impossible because, "what is this starting forth, beginning, coming

into existence, but an action, which is a quality of an object not yet in being, and so not

possible to have its qualities determined, nevertheless exhibiting its qualities," (PWMS

1.35). Her argument for continuance spans both these passages and a chapter dedicated to

the subject in the Essays. In an effort to make it more accessible, the premises of the

argument have been synthesized as follows:

P1 Beginning to be is an action or quality of an object which is not yet in being.

P2 Something not yet in being cannot act upon itself or the "non-entity" to come into being - something cannot cause itself to be or else it would have to have already been exhibiting qualities and must already exist.

$\mathrm{Cl}$ Anything which begins has a cause, external to itself, for its beginning.

P3 Objects which begin to be are dependent on their causes.

$\mathrm{C}^{9} \quad$ An object cannot depend on itself nor on "nothing" for its existence.

P4 Sensations (or internal objects) are sensible qualities.

$\mathrm{P5}^{10}$ Internal objects, as sensible qualities, cannot be the causes of our sensation because they are not independent of the mind.

P6 If internal objects cannot be causes of sensations, some other objects must act as cause (from P1-C1).

C3 External objects are the cause of our sensations.

P7 ${ }^{11}$ External objects cannot begin to be when we have a sensation, this would be the same as claiming that sensations cause external objects.

P8 If sensations cannot bring other sensations into being, and sensations cannot bring external objects into being, external objects must continue to exist outside of sensation

C4 Because there is at least one sensation, there is at least one continuously existing external object

\footnotetext{
${ }^{9}$ Evidence of Shepherd's arguments from P1 to $\mathrm{C} 1$ can be found in PWMS 1.35-39, as she challenges notions of self causation and tries to answer Hume's question of whether everything which begins must have a cause.

${ }^{10}$ This mirrors Shepherd's earlier challenge against Berkeley with regards to the organs of sense. As well, it is reiterated in Essay VI (PWMS 2.296) when she agrees with Berkeley and Hume that sensible qualities are incapable of acting as cause because of their dependence on the mind (she believes they do not take this argument to its full conclusion).

"The argument for synchronicity, as will be presented later, requires that causes at least be in existence for some interval before their effects are brought about.
} 
Since all objects that begin to be cannot hold this capacity within themselves they must all rely on something as their cause. "Nothing" cannot have or express qualities, otherwise it would be something. Thus it is impossible for things to begin in and of themselves since this would amount to being created from nothing. Since sensations are caused by something this places them in the category of effects. What prevents them from becoming causes is that as the perception of sensible qualities, rather than general qualities, they are absolutely dependent on both their external objects and the faculty of sensation for their existence. Thus internal objects cannot bring other internal objects into being, nor can they cause the being of External objects. By this means we can conclude that the existence of External objects, while attested to by the existence of their internal objects, is not predicated by them.

Hume argues that it is insincere to simply assume that a cause is necessary, for it is, "neither intuitively nor demonstratively certain," that everything which begins must have a cause of its beginning to be (Hume 1998, 50). He believes that when we make such claims about causation and beginning to be, we suppose an answer in the very question, and do not consider that it may be possible for something to begin to be without cause (Hume 1998, 49). This is not the solution that Shepherd wants to present; rather she insists that where sensations are concerned, their very nature necessitates a cause which is external to them, independent of them, and exists continuously. She dodges Hume's accusation of assumption because she is not creating an infinite causal chain. Sensations do not turn into causes of other sensations, and so sequence is not the defining feature of causation. Synchronicity forms this definitive character, and there is no "causal chain" for sensations, per se, simply because they can never turn around to become causes 
themselves. This answers Hume's challenge, because she is not making any claims about the causal roots of external objects, she is not presupposing that they must have a cause for their beginning to be. That is a question she must answer separately of the conversation about sensation. For the time being, a sufficient ground for causal relationships between external and internal objects has been built, which will enable Shepherd to lay down the premises of her theory of sensation and necessary connection in further detail. However, the notion of continuity also opens the door to questions about the identity and persistence of both internal and external objects through change because of how she understand objects as masses of qualities constantly interacting and changing the combinations of qualities they possess. She does not address this specifically, but the properties of both objects and their relation to one another is where a solution can be found.

\subsubsection{The Problem of Identity}

Examining the continuity of external objects naturally raises questions of identity and persistence through change. In addressing this concern we must set aside external objects for the moment and look more specifically at internal objects. This is necessary because it is internal objects which allow us to form ideas and beliefs about the external world. Understanding how these objects relate to each other and the external world will help us understand whether internal and external objects maintain their own identity through change, and whether this is necessary to Shepherd's account of causation.

In On Cause and Effect, she states that,

Effects are nothing but those same conjunctions of qualities, which are in other words admitted as similar causes, in the supposition of the question [of whether like causes produce like effects]. The objects (whose union is necessary to a given 
result,) must certainly exist, antecedent to such an union. But it is in their UNION, there exists those newly formed objects, or masses of qualities called Effects, which are therefore identical with the similar cause; for in this union, Cause and Effect are synchronous, and they are but different words for the same Essence.

(PWMS 1.57)

First off, there is an identity implied between causes and effects. This is because of the representative/reflective nature of internal objects that results from their dependence on external objects, and as a necessary consequence of cause and effect existing synchronously. This synchronicity amounts to their concomitant existence when causation occurs based on her belief that if cause and effect were merely adjacent there would be no metaphysical overlap to account for the change, which would be the same as claiming that the change was caused by nothing. This synchronicity is a proposition that will be examined in chapter two when looking more closely at causation itself.

This passage also emphasizes that objects are collections of qualities. Keeping in mind that external objects are collections of qualities-general and internal objects are collections of sensible qualities, internal objects in this particular iteration are synonymous with effects ${ }^{12}$. The sensible nature of these effects is derived from the physiological compilation of information gathered from our sense organs at any given moment. Shepherd states that,

there are two sets of OBJECTS in nature; viz. the EXTERIOR OBJECTS, the acting causes of nature, independent of the senses; the INTERNAL OBJECTS, the sensible effects of these, when meeting with the human senses, and determining their specific qualities upon the mind.

(PWMS 2.XIV)

Effects are supposed to give continual reference to their objects. If they are masses of qualities rather than a singular entity, what property within them grants them identity? If

\footnotetext{
12 The majority of my discussion of cause and effect is specifically conducted within the consideration of the causal relationships present between external and internal objects within sensation only, and does not necessarily pertain to the causal interaction between external objects.
} 
we remove any specific quality we will find that there is no specific quality that forms the essence or can grant identity to an internal object. In this sense, Shepherd would agree that there is nothing inherent in the effects themselves that gives them identity. Rather, they gain it from their causes, since like causes produce like effects and effects depend on their causes. The relationship of necessity between effects and causes, the necessity that effects must inhere in their causes, guarantees that qualities, which are assembled into recognizable objects by the faculties of sensation and reason, make actual reference to and have actual identity with their external objects. This means that in every case of certain masses of qualities, it makes reference to the same object. It is much like a social organization. Although we cannot say that any one member forms the identity of the group, together in their various combinations they are always analogous with it. A specific apple to the senses, even after it is found to rot, will still be the same apple because the collection of qualities makes reference to its external object.

On the external side of this story, the interaction between external objects to create new objects must also allow room for identity. Though any given external object may have rearranged some of its qualities, it must in some sense remain persistent through change, both when this change is happening within the external world and when this change consists in the creation of sensations. This is part of why Shepherd argues so insistently for the continued existence of external objects over their self-creation or creation by sensations. Whatever the specific characteristics of external objects may be, these objects are not destroyed in the process of causing sensation, or this would present a problem for synchronicity, because of the need for these objects to overlap. 
Whether causation takes the form of change, creation, or stasis, in all cases of sensation it is change that is being perceived. Even in situations where we bear witness to the continuance or "unchanging" state of something there is a metaphysical change taking place. At its most basic level, this change is persistence. The issue of persistence is concomitant with the issue of identity. Though stated in different terms and used to describe different circumstances, both change and persistence force us to consider the nature of the objects we perceive and whether they maintain some form of identity throughout time. As we have seen, Shepherd argues that we ought to be adverse to the idea that objects come into and out of existence. Both through inferential reasoning, and logical analysis, we find that objects must maintain a sense of identity in order to accurately account for their appearance at the "irregular call of the senses", and beyond this, their particular metaphysical makeup necessitates that they do.

It is most important for Shepherd to establish that external objects maintain their identity, even after they mix and combine their qualities. If she can prove that they do, then the identity of internal objects follows as a consequence of their dependence on their external objects. Once convinced of the independent and continuous nature of external objects, their identity through time is guaranteed.

Effects, understood as evidence of the machinations of an external and unknown world, are sensible effects and are the internal signs of external change. Shepherd explains that, "an Effect is the produced quality exhibited to the senses... an object may be defined, a combined mass of qualities; the result of proportional unknown circumstances in nature, meeting with the human senses," (PWMS 1.63-64). This filter or interpretation of the world is what we are actually speaking about when we use the word 
causation in the discussion of sensation. Any particular interaction between external objects, unless it is observed, is not to be considered the same as causation in this sense.

This is because causation under these terms is concomitant with the sensations that it creates. While causes are considered to have the power or potential to act as cause when they are unobserved by us, it is only their potential to cause sensations within us that this power refers to (PWMS 1.63-64). Whatever the character of the interaction between external objects may be, they can only be considered as the causes of our sensation while they exist synchronously with them, and in the process identify with them. Now that the significant characteristics and challenges surrounding the notion of external objects have been examined, we can start to understand internal objects in relation to external objects.

\subsection{Internal Objects and their Relation to the External World}

We have already seen to a small extent that internal objects depend on external objects, but the exact nature of this relationship ought to be examined from the side of internal objects to gain a broader picture of their character and important metaphysical role in Shepherd's causal theory. Being dependent on sensation, an understanding of perception is necessary for an effective discussion of their characteristics. Setting forth a general notion of perception, Shepherd states,

in the general conscious perception of sensible qualities, are included the knowledge that the organs of sense are used, as mechanical instruments acted upon by certain causes, and the IDEAS of these causes. And this conscious use of the mechanical action of the five senses in relation to other beings than the mind, is a very different part, or kind of universal idea of perception, from mental consciousness of PARTICULAR SENSIBLE QUALITIES only; which is also another part, or kind of the general notion of perception ; which general notion includes every species of consciousness whatever

(PWMS 2.202-203)

Perception is the active formation of internal objects by the senses. Perception is the complementary action of the organs of sense which interact with external objects to form 
our sensations. In some accounts of perception it is a passive faculty, receiving ideas or having sensory data imprinted upon our senses. Shepherd believes that these accounts gloss over some very important characteristics of sensation in general.

Berkeley's idealism portrays all physical objects in much the same way that Shepherd describes internal objects. As a system of metaphysics which places a great deal of emphasis on distinguishing objects of sense from external objects, Shepherd' theory must address the notions of objects and perception that Berkeley presents. Her main criticism is (as I have discussed) against his equivocation of sensation and the organs of sense, but a secondary and related critique she offers is of his notion of consciousness and how ideas of objects are acquired by the senses in general. She begins by setting ground rules for discussion of internal objects and sensation. As we have seen before, she explains that,

Inward existence is the capacity for sensation in general; outward existence is the exciting cause for some sensation in particular. The one is the very mind itself, or the power of thought and feeling; the other is a motive, or cause for a particular kind of it.

(PWMS 2.41)

This differentiates the two modes of being as outward being and inward being or conscious being. For Shepherd, it follows that,

all consciousness whatever ought to be ranked under the one generic term, sensation; and that these should be divided into the sensations of present qualities; sensations of the ideas of memory, sensations of the ideas of imagination, sensations of the ideas of reason, \&c. Thus simple sensation has many varieties of kinds. When it refers to no other existence than itself, it should be considered as sensation properly and immediately. In this sense we have the sensation of an idea; but then idea refers to an existence always considered independent of sensation; which idea is only its sign, representative, IMAGE, or whatever it may please philosophy to term it. Therefore our sensations include the notion of existences, which have existed, may exist, will exist, must needs exist, but whose qualities are not presently determined upon the mind.

(PWMS 2.135-136) 
Here, every conscious act of the mind is subsumed under the heading of sensation; this is similar to Brown's conjecture that perception cannot be considered as a faculty of the mind separate from other consciousness. Thus every activity of the mind is related to sensation is some form or another. This also explains how the contents of the mind are capable of being sensed, since ideas when we "have them" are not ideas, but sensations of ideas and memory. Shepherd's framework here does not immediately seem to clash with Berkeley's idealism, since we are capable of sensing ideas. On two points they differ, however: that the organs of sense are impressed with the ideas of sense, and that sensation for Berkeley is a passive faculty. In Berkeley's Dialogue 1, Hylas attempts to save external objects by distinguishing objects and the act of sensation more accurately. To him, perception includes both an act of the mind, and something which exists external to the mind. Philonous is unconvinced by his definitions, for it is contradictory to suppose that a part of perception should be capable of existing in an unthinking object while the act itself is inherent to minds (Berkeley, 134). Philonous' challenge to Hylas is geared towards challenging the active nature of perception. Hylas argues that perception is active the volitional sense. Philonous argues that this is the incorrect way of understanding perception, since there is no room for will in our sensations. We may choose to open our eyes, but the colours we see are not subject to our will (Berkeley, 135-136). If Hylas holds onto his definition, even after admitting that he agrees with Philonous, all that remains of perception is something outside of the mind, which is clearly contradiction. However, from Shepherd's point of view, this conversation proves something very different than the claim that perception is passive. 
Berkeley believes perception to be passive, but Shepherd believes his equivocation between the senses and sensation clouds this interpretation. Philonous does not give us a reason to believe that there is nothing external of minds related to perception, so much as illuminate the difficulty that arises when we claim that the content of sense is independent of act of sensation itself. This is the same challenge that Shepherd levies against Berkeley, but he seems unaware of the implications of Philonous' dialogue. Shepherd believes that Berkeley is right on one level; there is nothing of perception which is independent of the mind; however, perception is an active combination of sensations and reason, not merely a passive experience of the world. By asserting that objects are ideas Berkeley recognizes their mind dependent nature, but by denying their external counterpart and activity of the faculty of sense Shepherd believes he denies minds any power whatsoever. Since for her, all consciousness whatever is grouped under the category sensation, all consciousness would then have to be considered as passive and all the power of the mind or will vanishes from every aspect of thought. When Berkeley does away with the will of external objects, Shepherd believes he puts the will of God and our own minds in jeopardy because they also exist external to sensation. His separation of the different aspects of the mind -such as imagination, volition, and sensation from each other - would save aspects of our experience from this dissolution, but Shepherd does not wish to separate these aspects of consciousness.

Shepherd admits that this potential pacification of our minds isn't Berkeley's intended stance; she believes it is a consequence of his misunderstanding about the nature of objects and sensation. She explains that,

An object imprinted on the eye, for instance, must mean, (even in Bishop Berkeley's sense,) an object rendered conscious by the use of the eye; but what is 
the use of the eye itself, other than a conscious sensation, or action, supposed to involve the knowledge of an object, EXTERIOR to, and INDEPENDENT of that mind, to which it serves as an instrument of perception? For unless the whole subject in question is granted, the consciousness of the use of the organs of sense, can but be considered as some "sensations and ideas," which introduce onto the mind, OTHER "sensations and ideas." Yet Berkeley evidently considers the use of the organs of sense, as a circumstance distinguished and different from "ideas and sensations ;" because he considers that "god by set rules and methods, called the laws of nature, works upon and with the senses, in order to create ideas of sensation, objects of sense every moment." He thus makes an essential difference between the two powers in nature, without marking out any criterion of distinction by which the mind may recognize any such difference between them ; the senses, therefore, in his notion of them, are as necessary, to be acted upon "by these set rules and workings of a spirit," as they are in order to be worked upon by real extension, \&c. in the language of the anti-idealists... it appears, then, that the "senses" in relation to the actions of a spirit, must at any rate be something extra to the consciousness of their use. They are something in Berkeley's sense by which the spirit we depend upon introduces "ideas in our minds," but they are not as yet sensations in a mind, for it is by them sensations and ideas are introduced into the mind. The consciousness of the use of the eye could not introduce light... the organs of sense are at least, even in Berkeley's sense, some objects... which must needs exist as continuous existences, unknown and unperceived in their qualities, in order to account for the creation of sensations and ideas in the mind.

(PWMS 2.225-227)

Shepherd believes that in his own formulation of objects and sensation, Berkeley admits

to some sort of external continuous existence, namely the organs of sense themselves, which relates back to her accusation of his equivocation on the term sense. He cannot attribute these to ideas within the Divine Perceiver's mind, or else even we are figments of an imagination. This would be the extended result of Berkeley's conclusions from Shepherd's perspective, since, if there is nothing external to which all of our sensations about ourselves refer, we have nothing which gives us any identity. We end up as figments in the imagination of God with no power and no real existence in the world. Unless Berkeley is willing to give up all of our ideas and sensations and even our minds as independent to ourselves, he must still place faith in an actually existing framework for perceptions and ideas that is distinct from the Divine mind. He must make this decision 
because the ideal objects he describes, like Shepherd's internal objects, are not the things which make up the world; they are merely representations of it within our consciousness. While the source of these ideas may be different, his Divine and hers mundane, they nonetheless exist outside of us and thus there must be something about our minds and sensations that stand apart from these things. For Shepherd these sources are external objects, for Berkeley, the Divine mind is the only solution offered, but Divine substance is perhaps enough to provide metaphysical grounds for ideas. It is not enough that they should subsist in a mind by Shepherd's account, for they must have their original material from reference to something which actually exists.

\subsection{Linking External and Internal Objects through Causality}

With a much more developed sense of internal and external objects in hand, we can now turn our attention to the nature their relationship. We have already seen aspects of the dependence that internal objects display on their external objects, but Shepherd believes that there is an important causal account of this dependence which must be explored in greater detail. At base, she will argue that the relationship between external and internal objects, the causes and effects of sensation, is one of necessity. The peculiar nature of the necessity she advocates for marks her as a unique thinker, and also poses interesting challenges to traditional accounts of causation and necessary connection. In the following chapter these notions will be explored in detail alongside a framework for theories of causation created by briefly examining the theories of Shepherd's contemporaries, as well an examination of the interpretation of Shepherd's theory of necessity by Martha Brandt Bolton. 


\section{Chapter: Shepherd's Theory of Causation}

\subsection{Framing Shepherd's Theory of Synchronicity}

Now that we have a clearer understanding of how Shepherd characterizes the two kinds of objects, we can begin to take a proper look at how external objects act as the causes of our sensations, and where she believes errors commonly arise in traditional accounts of causation. Shepherd's account of causation is distinguished from those she criticizes because of the notion of synchronicity, which posits that causes must exist concomitantly with their effects. This is central to her theory, and is also the notion that will perhaps present the greatest challenges to its intelligibility. The idea of synchronicity is threaded throughout her entire metaphysics, not just as a consequence of her definitions and arguments, but as the very foundation of the necessary connection at the heart of causation. By taking a look at several theories of causation, with particular attention on their presentation of necessary connection, and reviewing sequential accounts of causation, like Brown's, and the debate which surround them, we will be able to build an appropriate frame for examining synchronicity, external and internal objects as they take part in this relationship, the issues that arise when considering interaction between external objects, and the three kinds of necessity inherent in her metaphysics.

One of the most common errors Shepherd points to is the incorrect association of sensations with causes, rather than effects; Brown is a particular target of this challenge. She explains that, "I consider it to be the want of separating our perceptions from their causes, which has given occasion to the false notion, viz. that of the successive effects perceived, the antecedent are causes and the subsequent are effects," (PWMS 2.306). 
This is in response to Brown's claim that "Priority in sequence observed, and invariableness of antecedence in the past and future sequence supposed, are the elements, and the only elements, combined in the notion of a cause," (Brown 2010,49). Shepherd believes that this is to confuse sensible effect of sequence with a cause, and that this confusion is ultimately created by a failure to recognize the distinction between external and internal objects. This is a confusion she also challenges Hume for having based on his claim that, there are three requirements for objects to be considered causes contiguity, priority, and constant conjunction- and that for any object, "we perceive only their sensible qualities: and what reason have we to think that the same powers will always be conjoined with the same sensible qualities?" (Hume 1998, 35). Hume believes that knowledge of cause and effect can only be arrived at through habit because of the essential sensible nature of all of our knowledge of objects. The implication for Shepherd is that this leads him to skepticism toward actual causation by external objects. As we have already seen, internal objects can only ever fit within the category of effects; they are incapable of acting as causes because of their dependence on external objects and upon the faculty of sensation. As well, internal objects are the qualities perceived by the mind that constitute our impressions of the world. As such they cannot exist independently of the mind because they are intimately connected with it. Independence and externality are characteristics of external objects alone. Though independence and externality may not be the only characteristics of external objects, Shepherd believes they are necessary in order for any object to act as a cause. If she can establish the truth of this claim, it will become clear that internal objects - and thus sensations and sensible effects- can never act as causes. 
Shepherd's primary justification for this claim comes from her examination of the nature of effects, and how the understanding processes perceptual experience and arrives at causal knowledge. To help give a contextual frame to Shepherd's theory of necessity examples of some variations on necessary connection, as found in Malebranche, Hume, and Brown, will be most useful.

One important thing to remember in the discussion that follows is that the scope of this discussion is limited to causation as it pertains to sensation. While Shepherd and the philosophers she critiques all have important metaphysical claims to make about causation within the external world, beyond the limits of sensation, those opinions are not of concern here. They are important to examine as part of the larger project of reconstructing Shepherd's theory, but currently beyond the importance of establishing her theory of sensation and epistemic justification for causal belief. While avoiding the larger discussion on causal necessity as a whole may seem remove vital elements of the theories discussed below, I believe that everything these philosophers say about causation must also pertain to the causes of our sensations.

\subsection{Malebranche, Hume and Brown: Three theories of necessary connection}

Malebranche is one of the figureheads for Occasionalism, and his vision of necessary connection is shaped by the omnipotence of God. While finite objects appear to interact with each other causally they are only occasional causes, God is the true cause of any event (Malebranche 1997b, 448).

For Malebranche, the power to act as cause is intimately tied to the will. As such, bodies are not even capable of moving themselves. He explains that if a body were capable of moving itself it would have to exhibit some capacity to will. Since mere 
bodies to not have this capacity, they cannot move themselves, and if they cannot move themselves, they are incapable of moving anything else (Malebranche 1997a, 110-111). Since we only have two sorts of ideas, those of bodies and those of minds, and since he has determined that bodies do not have the power to move bodies, minds must be responsible for that movement. However, our finite minds do not display any necessary connection between will and actual movement; it is the case that what we will does not always come about. A true cause is

one such that the mind perceives a necessary connection between it and its effect. Now the mind perceives a necessary connection only between the will of an infinitely perfect being and its effects. Therefore, it is only God who is the true cause and who truly has the power to move bodies.

(Malebranche 1997b, 450)

Therefore God is the ultimate cause, since God is the only being who, by definition, cannot fail to achieve their will.

The appearance of causation between objects still needs to be accounted for, however. To do this, Malebranche defines two kinds of causes, natural and true causes. He explains that

when a ball that is moved collides with and moves another, it communicates to it nothing of its own, for it does not itself have the force it communicates to it. Nevertheless, a ball is the natural cause of the motion it communicates. A natural cause is therefore not a real and true but only an occasional cause, which determines the Author of nature to act in such and such a manner in such and such a situation.

(Malebranche 1997b, 448)

So while natural causes appear as causes only on the occasion of some event taking place,

God is the true cause of these events. Malebranche believes that for something to continue to exist, God must will that it be the case. When God wills something to exist he wills it to be in a particular place in a particular way. If he stops willing their existence they cease to be. Thus at each moment of an objects existence, it is only ever existing in 
the way God wills it, and no other objects or minds have a true effect on it. Thus God is the only true cause (Malebranche 1997a, 112). All other causes are appearance, and do not truly act as causes on a metaphysical level. Thus there is no conflict between the efficacy of God's will and natural causation, because natural causes are not real causes. Hume, like Malebranche believes that we cannot find necessary connection and thus real causation between (natural) causes and their effects. Since conceptual analysis of our ideas of cause and effect is not enough to give us an idea of necessary connection, Hume finds that it is very easy to conceive of causes and effects as distinct things without any connection. He even goes so far as to say that this conceptual distinction could also be a real distinction, insofar as it does not present any contradictions or absurdities (Hume 1998, 48). The import of this claim is not that causes and effects are actually distinct, without any necessary connection, but rather that we cannot argue that necessity is understood a priori, through reason alone.

Shepherd agrees with this sentiment in the Essays, when she stated that intuition and other forms of a priori reasoning work equally well to argue both for and against the principles of necessary connection. She states that,

The proof of every existence which others refer to "instincts," "primary laws of belief," "ultimate facts," "immediate knowledge by the senses," or other means, the which do truly leave the objects of which they testify wholly without any proof whatever; for, "that we are incapable of thinking otherwise than we do," can itself e no reason that we think rightly. The same instincts, laws of belief, immediate knowledge by the senses, do, in the course of every twenty-four hours, afford the same kinds of proof for the independent existence of objects which men admit to be non-existent without a doubt remaining on the subject.

(PWMS 2.222-223)

However, Hume goes a step further. He challenges the idea that everything must have a cause. He explains that, 
everything, 'tis said, must have a cause; for if any thing wanted a cause, it wou'd produce itself; that is, exist before it existed; which is impossible. But this reasoning is plainly inconclusive; because it supposes, that in our denial of a cause we still grant what we expressly deny, viz. that there must be a cause; which therefore is taken to be the object itself; and that, no doubt, is an evident contradiction.

(Hume 1998, 48-49)

This is a valuable challenge to answer, as the "no self causation" argument plays a heavy role in some of Shepherd's earlier arguments for the separation of the causal roles of internal and external objects, as we saw. While Shepherd argues all sensations must have a cause, this is not necessarily the same as asserting that all objects whatsoever must have a cause. Nevertheless, Hume brings an important question to the foreground of the debate surrounding necessity, namely that, "the true state of the question is, whether every object, which begins to exist, must owe its existence to a cause; and this I assert to be neither intuitively nor demonstrably certain," (Hume 1998, 50). In response to this question, as it pertains to sensations, Shepherd argues for a very specific understanding of both necessary connection and sensation. ${ }^{13}$

Hume ultimately concludes that necessary connection is just a convenient idea of the understanding to explain the regularity of our experience. He argues that,

it appears, then, that this idea of necessary connexion among events arises from a number of similar instances which occur of the constant conjunction of these events; ...the mind is carried by habit, union the appearance of one event, to expect its usual attendant...this connexion...is the sentiment or impression from which we form the idea of power or necessary connexion.

(Hume 1998, 114) So necessary connection then, is simply the idea which arises from our customary experience of similarities between events. There are three possible iterations of this view that Hume could be holding in this instance:(1) that there is no such thing as necessary

\footnotetext{
${ }^{13}$ Her vision of necessary connection will be addressed in section 2.7 . The majority of chapter three will address sensation.
} 
connection and no real idea of it, but we think there is because of habit; (2) there is no necessary connection between objects but the idea of it is real and is based upon our experience of similar events; (3) we project these ideas of necessary connection onto objects in the world. In all three cases there is nothing immediately rationally accessible about necessary connection; the concept is only derived from habitual experience of similar events, not from anything essentially true about the world or how its parts interact. We think that there is a necessary connection between objects simply because it is convenient for the mind to make this association. The objects become "proof" for each other's existence in our thoughts and make it easy for us to recall ideas through association and contiguity (Hume 1998, 115) but there is nothing in the natures of the objects themselves which suggests that this is a genuine connection.

Brown's approach to causation and necessary connection is different again. He believes that objects do share an actual connection, one that is not simply appearance or imposed by the imagination. He believes that all causes are necessarily connected to their effects because of the invariable antecedence of causes to their effects (Brown 2010,4849). We attain knowledge of this invariable sequence and its necessity through our impressions about the world.

For Brown, the constant motion of everything in the universe is what leads us to understand causal priority. He explains that, "what seems to our eyes to be rest is continued motion. There is not a particle of the planet on which we dwell, that continues in the same point of space, during the instant in which we strive most rapidly to think of it," (Brown 2010,46). Everything that exists is in constant motion; this also includes our consciousness, which includes all of our sensations, thoughts, and emotions. The 
constancy of this motion would seem too pervasive to allow us to sort out the relationships between objects, but Brown believes that, "the great character of all these changes, however, is the regularity which they exhibit," (Brown 2010,46). Everything which defines the relation between cause and effect boils down to the sequence they exhibit. From our experience of the world we have, “...no other impression of relation than of a priority and subsequence that were limited to that particular moment..," (Brown 2010,47 ), in part due to the constant change, and also as a result of his understanding of power in general.

Power is the capacity of one object to affect another. Through reasoning, as Hume suggested, we cannot arrive at a concept of power in which one sort of object must necessarily always affect another. For Brown power is derived from the sequence itself; no one thing has the power to cause another except when we mean this to express that one object always invariably precedes another. He states that,

it is this mere relation of uniform antecedence, so important and so universally believed, which appears to me to constitute all that can be philosophically meant, in the words power or causation, to whatever objects, material or spiritual, the words may be applied. If events had succeeded each other in perfect irregularity, such terms never would have been invented ${ }^{14}$

(Brown 2010, 48)

Causal power is very narrowly defined in terms of sequence, and in fact objects themselves could be considered to have no real power in the traditional sense. Instead, "power" is an expression of the position of priority and contains no metaphysical characteristics other than this. For Brown the whole order of events is completely

\footnotetext{
14 This may seem a weak conception of something supposed to be invariable in sequence, but Brown seems to be indicating that it is "mere" in that it is the only characteristic of causation and necessary connection, and that there is no other source of causal power between objects. This is sympathetic to the Humean conception of necessary connection, but I believe Brown thinks this relation is more than just a product of the human mind.
} 
established, and it is in this that we can be assured that our causal knowledge and knowledge of the world in general is true. We form an instinctive understanding of this relationship of invariable sequence, and our definitions, though occasionally misleading, do speak some truth about these relationships. Brown explains that,

We give the name of cause to the object which we believe to be the invariable antecedent of a particular change; we give the name of effect, reciprocally to that invariable consequent; and the relation itself, when considered abstractly, we denominate power in the object that is the invariable antecedent; susceptibility in the object that exhibits, in its change, the invariable consequent.

(Brown 2010,48)

Furthermore, all that we can say about the necessity between causes and their effects is

this sequence. There are no other aspects to this relationship, "priority in the sequence observed, and invariableness of antecedence in the past and future sequence supposed, are the elements, and the only elements, combined in the notion of cause," (Brown 2010, 49).

Shepherd believes that Brown's understanding of necessity relies too heavily on sequence. Whereas for her, the synchronicity of cause and effect is what binds them necessarily, in Brown's account there is no room for synchronicity because the constancy of change does not allow causes and effects to exist in anything other than a successive fashion. Shepherd challenges sequential readings of causation, believing them to be incomplete accounts. They are incomplete rather than false outright by virtue of the fact that, while they ignore what she would consider the external half of causation, they do make relevant attempts to describe the sequence of experienced events.

\subsection{Antecedence and Subsequence}

Shepherd repeatedly criticises sequential accounts of causation for their emphasis on antecedence as a primary characteristic of causes. She agrees that the causes of 
sensation must exist prior to their effects, but rather than this priority marking something essential in the relationship between cause and effect, she believes it is simply a byproduct of the temporal nature of our experience.

While Shepherd argues that attributing sequence to the relationship between cause and effect is incorrect, it is not her only point of contention on the subject. In our look at Malebranche, Hume and Brown, we caught a glimpse of the varying views surrounding the role of sequence. Hume openly doubts whether the observed sequence of events is strong enough to grant us an idea of necessary connection. The supposed suspension of effects, as well as the performance of miracles, is the greatest source of his doubt. While he does believe that sequence is the one thing we can claim to know about causes and effects, it gets us no closer to true knowledge because such priority doesn't provide any logical or intuitive requirement for necessity. Brown, on the other hand, believes that priority is the only distinguishing characteristic between effects and causes, and that the invariableness of this relationship enables us to interact with the world effectively and form true beliefs.

Shepherd claims that the philosophical difficulty in assessing necessary connection that arises from antecedence accounts is due to an incorrect interpretation of experienced events as causes rather than effects (PWMS 2.306). She believes that sequential accounts of cause typically either confuse effects for causes, or take antecedence as the primary attribute of causes, and allow it to define the relationship between causes and effects. In either case, the only thing that can connect them is the sequence in which they occur. While this may be unproblematic to the internal operations of sequential accounts, Shepherd believes that sequential accounts are unable to provide 
any justification for causal beliefs. In her 2011 paper on Shepherd, "Causality and Causal Induction", Martha Brandt Bolton points out that we easily mistake our observations of change with cause, but with careful consideration and reflection upon the principles that Shepherd has given us, we can come to understand that, "the accomplished conjunction of fire and $\log$ is necessary and sufficient for ignition; combustion and its cause are strictly coextensive in time" (Bolton, 244). She supports Shepherd's synchronous account of causation, believing that the vivacity with which we experience sequence leads us to make incorrect attributions about the sources of the content of our sensations. Shepherd states that, "although an object, in order to act as cause, must be in being antecedently to such an action; yet when it acts as a Cause, its Effects are synchronous with that action, and are included within it," (PWMS 1.49-50). The specifics of this synchronous relationship will be revisited shortly; the important thing to draw from this is that while cause and effect are synchronous in the moment of causation, this does not discount the notion of sequence. Sequence is a sensible quality, or sensation, and as we know, sensations cannot be causes.

Shepherd contends that although we are not wrong in recognizing the sequence of events, we must remember that these experiences are just telling the sensation/effect side of the causal story. Antecedence and subsequence are "causal" characteristics of the relationship between various effects, but the relationship between causes and effects is one of synchronicity, as both she and Bolton point out.

Our sensations of fire and log, for example, are the internal representations of external objects. Our sensation of the resulting combustion is the internal representation of a change taking place between the natures of the fire and the log. These sensations are 
connected to each other through their relationship to their external causes. Both sensations are experienced in sequence, yet this sequence points only to the existence of the fire and $\log$ before their interaction. Each sensation can be seen as a stage of the process of change, but none are causes outright. To make that assumption would be to conflate the evidence for an object's existence with the nature of that object (Bolton, 244). If we keep the distinction between cause and effect, and external and internal objects in mind, Shepherd's theory of synchronicity becomes much more accessible.

\subsection{Synchronicity}

As we discovered in Chapter One, external objects, and hence causes, are held to three criteria: externality, independence, and continuity. With these criteria, we can start looking at where errors are introduced into accounts of causation according to Shepherd. One of the difficulties is the blurring of the line between cause and effect. This blurring is so easy and natural to do, that it even appears to happen in her work, especially in $O n$ Cause and Effect when she is first discussing synchronicity. Unless forearmed with the definitional framework she sets up in the Essays, the discussion of synchronicity can easily be mistaken to imply that cause and effect are one and the same. For a great number of reasons, this conclusion is incorrect, and despite the difficulty of reading $O n$

Cause and Effect, careful attention will show that Shepherd is consistent in her distinction of internal and external objects.

Most often, the confusion between causes and effects arises because of the tendency to accept antecedence and subsequence as integral to causality. Shepherd admits that experience necessarily happens in a temporal fashion; we observe sequences of effects in time and naturally order them in a loose series. Because of the causal indicators 
that we pick up on, such as the tendency for certain effects to happen in regular patterns, it is easy for us to associate this series of effects with the causal chain of events, wrongly assuming that one effect causes those which follow it. However, Shepherd points out that although it may seem intuitive to classify effects in this manner, it can obscure external objects as the true causes of our sensations. If we want avoid this particular brand of confusion, we need to remember that all objects,

when considered as causes, should always be considered as those masses of unknown qualities in nature, exterior to the organs of sense, whose determination of sensible qualities to the senses forms one class of their effects; whereas philosophers, (with the exception of Berkeley,) and mankind in general, look upon qualities AFTER determination to the senses as the causes, the antecedents, the productive principles of other masses of sensible qualities, which are their effects or subsequent.

(PWMS 2.127)

The first way of understanding cause and effect, presented by Shepherd here, requires that we look beyond our experiences and sensations, and recognize that they are acquired from something outside of our capacity for sensation. When we grant that effects are merely the inward signs of outward change, we immediately recognize that their sequence is, for the purpose of defining causal relationships, unimportant. The second way Shepherd speaks of only takes causality into consideration after we have witnessed something. This way of considering causality does not take into account that there is something beyond sensation which causes them, or that all the objects we recognize internally are masses of sensible qualities and as such cannot be causes. This understanding of the relationship between cause and effect relies heavily on the temporal distinction of antecedent and subsequent objects or events as we witness them, but does not consider their representative role. 
As such, Shepherd believes that antecedence and subsequence are inadequate markers of cause and effects because they do not reflect the necessary connection between sensations (effects) and external objects (causes). This necessity is found within the synchronicity that causes and effects exhibit, and within sensation it is found in the dependence of internal objects on their external objects. Any necessity that may exist between external objects is undetermined for the moment, but it could be assumed that it is the same necessity formed in the synchronicity of cause and effect. The notice we take of antecedence and subsequence marks that we have been affected by a change that is taking place in an object, but neither idea is capable of giving us an understanding of the true causes of an event, nor the necessary connection between its objects and its sensations. Shepherd explains that,

'Antecedency and subsequency' are therefore immaterial to the proper definition of Cause and Effect; on the contrary, although an object, in order to act as cause, must be in Being antecedently to such action, yet when it acts as a Cause, its Effects are synchronous with that action, and are included in it... for effects are no more than the new qualities, of newly formed objects. Each conjunction of bodies, (now separately in existence, and of certain defined qualities,) produces upon their union those new natures, whose qualities must necessarily be in, and with them, in the very moment of their formation.

(PWMS 1.49-50)

This synchronicity is the shared temporality of an external object and internal object it creates in the mind. The object that causes our sensation exists before it acts as cause, but in the moment of creation they exist simultaneously, inseparably linked by the act of causation and the dependence of the effect on its cause.

One problem seems to crop up for synchronicity within this passage: the tendency to temporally collapse cause and effect because of this synchronicity. Since the moments of cause and effect are synchronous, there seems to be little in the way of preventing us from claiming that each step of the causal chain is synchronous and thus collapsible into 
a single moment. This difficulty with Shepherd's talk of synchronicity is due to a possible ambiguity in its application. Synchronicity could mean that cause and effect are essentially the same, or that the distinction is inconsequential. This however, is to apply synchronicity to an already sequentially biased account, and still mixes causes and sensible effects into the same object category. For causal moments to collapse in such a way could only mean that the sequence of causes, which includes old effects that become new causes, share this synchronous trait and thus the first cause would be synchronous with the last effect, and any space between them would be indistinguishable. But what Shepherd actually intends by synchronicity is not simply a superimposition of the idea over sequential accounts of cause and effect. Recalling that the effects in question are sensations witnessed in sequence, and that sensations can never be causes, it is clear that this temporal collapse could never occur. External objects must exist before they act as causes, so there is at least one existence temporally distinct from effects. Effects also happen in sequence, an experience which Shepherd believes indicates something true about the world, namely that there is a sequence in causation. So, when we witness two events in sequence it is not some trick of the mind, but a representation of various causes acting at different times to create their effects. Shepherd explains that,

In short, concomitant, or "successive sensible qualities," are considered by all men when they come to analyze their notions, (and ought to be held by philosophers,) as concomitant or successive EFFECTS, arising from the different actions of an external independent object, meeting either at the same time, or successively, with different instruments of sense which it unites. - Thus, the antecedency and subsequency of certain respective aggregates of sensible qualities, must necessarily be INVARIABLE in like circumstances; for they are successive and similar effects, from successive and similar causes, instead of the succession itself forming essential cause and effect.

(PWMS 2.128-129) 
So while sequence tells us little of the relationship between cause and effect, it does guarantee to us that there is nothing false about our experience of time. This sequence also allows us to recognize that there is an invariableness of the relationship between causes and effects; certain sequences always seem to follow one another, in this she agrees with Brown. This sequence would be impossible if everything was to happen at once, and causes and effects were indistinguishable. This invariableness will be touched upon again later in the discussion of the three kinds of necessary connection, as it is important to Shepherd's distinction between the each of the different kinds of necessity.

I believe synchronicity is vital to Shepherd's understanding of causality because it derives from her arguments against self causation. It can be reasoned that if there was no overlap in the moment of causation, then we would be forced to recognize that effects were not truly caused by anything. Since "nothing" cannot have the power to act as cause and effects do not have the power to self cause, that synchronicity between cause and effect in the moment of causation is the only thing which can account for the creation of the effect. If the argument is made that a cause "vacates" its space to make room for the effect, it is the same as arguing that the cause ceases to exist so that its "effect" may immediately take its place. If this were the case, there would be no reason as to why we could not separate cause and effect as Hume proposes. There could be a conceptual distinction proposed between them. Since effects are "nothing but those same conjunctions of qualities, which in other words are admitted as similar causes," (PWMS 1.57 ) and "the union of two distinct natures, is the cause, producer, or creator of another; which must instantly, and immediately, have all its peculiar qualities; but the cause has not acted, is not completed, till the union has taken place, and the new nature is formed 
with all its qualities, in, and about it,"(PWMS 1.50) cause and effect cannot be separated in the moment of causation, otherwise there would be no object continuously existing to give existence to the new combination of qualities. This equally applies to sensible effects, and effects in general; the case could even be made that the necessity and synchronicity between sensible effects and their causes is even stronger, because of the added element of their absolute dependence on their external objects.

So what does this synchronicity look like and why is it so important that we believe Shepherd? First, to return to the ideas from chapter one: there are external objects existing in the world. When they come into contact with our senses, and are capable of displaying their qualities, they create within us sensations. Shepherd's argument is that these sensations are created at the same moment that the external causes act upon us. Yet rather than this synchronicity allowing causes and effects to form a bond of necessity, it is rather a symptom of that relationship between them. This necessity not only allows us to form true knowledge of the world, but also about the general principles which shape how objects in general interact with each other causally. These principles include, but are not limited to ideas such as synchronicity and the principle of sufficient reason. ${ }^{15}$ Shepherd believes that this knowledge is impossible to arrive at if cause and effect merely relate to one another in sequence.

\subsection{External Objects as Cause}

With several key distinctions now established between the nature of internal and external objects, as well as the relationship between them, we may turn to determining what it is that grants external objects their ability to act as causes. Their externality,

\footnotetext{
${ }^{15}$ This is an interpretation offered by Bolton and it will be visited again when discussing the three kinds of necessity.
} 
independence, and continuity are certainly enough to set them apart from internal objects, but these characteristics are not enough, alone or in combination, to grant causal power. Ultimately Shepherd will claim that necessary connection (in synchronicity) is where this power is derived. Malebranche, Hume, and Brown all believe that necessary connection is the defining character of causation, but they all disagree as to the kinds of objects that can act as cause. For Malebranche, causal power is directly related to the necessity that an object or a being's will comes about, and the only entity that fulfills this relationship is God. For Brown this necessity is derived from the invariable priority of causes to their effects, a sequence set in motion by the Divine Author. And for Hume, this necessity is an idea created by the imagination as a result of customary experience. Whether or not this is a genuine property of the real world, and what kinds of objects could hold this power (if any at all) is still a matter of skeptical concern for him.

For Shepherd, external objects are causes because they are necessarily related to their sensible effects; you cannot have an effect without there being a cause for it, and you cannot have a cause without it being capable of exhibiting its effects under the right conditions. Sensible effects themselves do not fulfill the specific condition to be considered causes, because they are part of a subjective internal experience; they are dependent on these external objects, and are themselves only signs of external change. Shepherd makes this distinction in part because she is not satisfied with Malebranche's occasionalist account, which denies all but one genuine cause, namely God. So, while on one level these theories seem to agree that necessity characterizes the power of objects to act as causes, they are incompatible because Shepherd needs there to be more than one object for the world to make sense. 
Occasionalism proposes that God is the only genuine cause, and that all natural causes simply appear as causes when God occasions them; in essence all objects are effects and there is only one cause. This is a problem for Shepherd because she believes that sensations give true reference to external objects as their cause and that the variety of sensations shows that there must be more than one cause. If God were the only object capable of acting as cause, she would argue that all of our sensations ought to reveal this in some way. Instead we are presented with a plethora of objects to match the variety of sensations. Shepherd contends that, all sensations, and all their varieties, must have causes or objects in nature as various as themselves which are the effects of those causes, or the qualities they occasion to the mind's perception. Contrary qualities must also have contrary causes. Thus the cause for motions cannot be the same as that for rest; nor for one place, (whatever place may be,) as that for a different place.

(PWMS 2.61)

For just as she argues that like cause produces like effect, in circumstances of difference there must be some different cause to account for it, (PWMS 1.58-59).

Shepherd argues consistently for the existence of a causally active external world because she believes that only through the relationship of necessity formed between internal objects and their causes can any knowledge be gained whatsoever. Additionally, if we posit God as the only cause, we must give up our concept of personal identity, and existence. Our identity would be subsumed into God's, something which very few theologians and philosophers are willing to concede as it not only challenges our traditional conceptions of self, but places a great burden on our notions of God to account for human characteristics. Malebranche himself assumes that humans exist independent from God in some capacity, but his ideas are irreconcilable within Shepherd's framework. This does not necessarily make his theories incorrect -as we have seen they 
agree that necessity is what gives causes their power- but it does show how Shepherd's theory is incompatible with subsistence models of causality. ${ }^{16}$ It is worth, at this time, setting aside the discussion of sensible effects to talk about the causal interaction between external objects in order to clarify some of the general principles of causality Shepherd proposes, and expose some of the difficulties with these proposition that remain unaddressed, before committing to an explanation of the three kinds of necessary connection that arise from these doctrines.

\subsection{The Interaction between External Objects}

There appears to be two levels of interaction taking place in Shepherd's theory of causation, the interaction between External objects and internal objects, and interactions between just external objects. In the first causal interaction an external object acts upon the senses and we perceive an effect. In this moment, cause and effect exist synchronously, but the external object which has acted as cause will continue on its way, possibly to produce effects again in the future. In the second scenario Shepherd presents a much more typical account of causal interaction: where two external objects interact to either change each other or create a new object. However, this relationship, though similar to the one shared between external and internal objects on one level, cannot be an identical relationship for one simple reason: sensible objects can never become causes.

\footnotetext{
${ }^{16}$ By "subsistence models of causality" I mean, in general, all those theories which hold that the existence of objects subsists in or is maintained by God. I suppose these to include occasionalist accounts of causality, as well as continuous creation accounts, and even Berkeley, because of the Divine perceiver. These do not include generally theistic accounts which merely posit that God had a hand in the creation of the universe, but is aimed to include those theories which necessitate his continued participation in the maintenance of the universe. Shepherd shows many tendencies towards a theistic view of the world, but she believes that necessitating His continued interference diminishes His perfection in some way (PWMS 2 Essay III, Essay VI).
} 
In chapter one, we dealt with the characteristics of objects and discovered that causes were incapable of being considered as sensible effects, which is to say that sensations can never be considered as causes. In traditional accounts of causation, objects can interact with each other to bring about new effects and even new objects. Shepherd believes that objects do interact with each other, but we cannot intend by this that sensations can be part of a successive chain of interactions. While they are the signifiers of outward change, they themselves do not participate causally in these interactions. It may seem contrary to propose that there is a kind of object whose existence includes the power to act as cause while there is another which existence precludes this power and yet they still interact with each other causally, but this dichotomy is what Shepherd uses to challenge other accounts of causation.

In On Cause and Effect she states that, "objects in relation to us, are nothing but masses of certain qualities, affecting certain of our senses; and which, when independent of our senses, are unknown powers or qualities in nature," (PWMS 1.47). These masses of qualities combine and mix with each other, exchange some of their qualities, and generally mingle; this forms a new mass of essentially new qualities. The masses of qualities when they are sensed are effects, but when independent of the senses can be either causes or effects depending on their relation to other external objects. Two parent objects meet and create new objects, or else they simple affect a change in one another, like when a billiard ball strikes another and exchanges its quality of motion for the quality of rest of the other. These interactions form a sequence of cause and effect, which can either be traced back infinitely or, more often finds its origins in God. 
Under Shepherd's account, this external interaction shares the characteristic of synchronicity we see within external/internal causation. In this way the new qualities or effects have dependence on their causes, but unlike sensations, these new masses of qualities supposedly have the power to themselves act as cause. She states that,

the union of two distinct natures, is the cause, producer or creator of another... Cause producing Effect, therefore, under the strict eye of philosophical scrutiny, is a new object exhibiting new qualities; or shortly, the formations of a new mass of qualities. A chain of conjunctions of bodies, of course, occupies time.

(PWMS 1.50)

During this perception of the sequence of sensible qualities it is easy to misunderstand the lack of causal power sensations have because they seem to share a similar relation to external objects which these objects share with each other. It is unclear whether taking note of the sequence of cause and effects as it occurs in the external world results in the same misunderstanding when we read sensible effects in this way. Arguably under this frame, the chain of conjunctive causes does in fact tell us something about causal relations, though synchronicity would still have to be the defining characteristic of necessary connection. The difference between the two accounts of causation seems to lie within perception itself. Because of their dependence on the mind, internal objects cannot have any causal power. Effects in the external world are not constrained by this particular dependence, so while they may inhere in their causes, this relationship would not seem to prevent them from acting as causes at a later time. When Shepherd speaks of "cause producing effect" she is referring to the moment of synchronicity, stating that a union of two objects into a new one is synonymous with this productive principle. No external object can be considered a cause until it produces an effect, and so it maintains the same independence externality and continuity found in chapter one, regardless of the kind of object its effect may be. 
When external objects combine direct knowledge of this interaction is not possible. If it were, the effects of this combination would be sensible effects. Since all we can observe of these objects is the sensible effects they produce, our understanding must undergo a further step to gather knowledge about these objects. Shepherd does not believe that knowledge of the external world is impossible; because internal objects represent their external objects, they also represent the relationships between these objects. When trying to separate the subjective content of sensation from the truths about the external world, the mind can undergo a mental arithmetic to discover these principles. She explains that,

With respect to the nature of unperceived objects I shall take notice, that we can dorm some ideas of their natures by subtracting from them EQUALLY that which is common to all, viz. the action of the instruments of sense and the mind... Now it is by separating the ideas of sensation in general from the ideas of particular sensations, that we gain the notions of existence which need not necessarily be sentient.

(PWMS 2.162-163)

Through recognizing the influence of the senses on the knowledge and judgment formation, actual knowledge of the operations of the world can be achieved by removing this common element and examining the ideas which remain. We see two snowballs combine to make a larger one, but the two original snowballs we perceived are not the cause of the new one, they are themselves the effects of some external objects, as is the appearance of the new snowball. But removing human sensation from the equation we can still discover something about these objects, namely that they are extended, and that their individual mass now shares a common space. We also know that there is a causal relation between these objects which shares some of the characteristics of the causation between external and internal objects. 
In the Essays she says something very similar to the statement from On Cause and Effect when discussing how external objects act as cause. She states that, objects, when contemplated singly as the efficient causes of nature, are to be considered in their outward unperceived state, and as yet unconjoined with each other...It is the union of all the objects absolutely necessary to any given end, which forms a new object, whose new qualities are the effects, or properties of those objects when uncombined; and which must be synchronous with the existence of the newly formed object...

(PWMS 2.123-124)

External unperceived objects unite with each other to form new objects, whose qualities are those of its parents. So no "new" qualities are being created per se, the new object is simply inheriting the qualities of the ones which united. A better analogy for this might be the combination of two boxes of blocks, one group red and one blue. The combined lot might be considered new but it has all the redness and blueness of the old boxes.

It seems that Shepherd is also indicating that objects are conjoining with each other when we witness their effects, so it is possible that there are two layers of causation overlapping each other at once: the interaction of external objects to create a new object, and the interaction of these objects with the senses to create their respective internal objects. All of these objects must exhibit some sort of necessary connection to each other to be properly considered as causes and effect. Shepherd proposes two sorts of necessary connection, that between cause and effect, and effects themselves, an idea which Bolton explores and explains in detail in "Causality and Causal Induction". I propose that there is a third kind of necessary connection, the connection between causes, and argue that this connection is implied because of how they both discuss the other two relations of necessity as expressed within synchronicity. 


\subsection{Three Kinds of Necessary Connection}

As I have argued, the idea of necessary connection is central to both the Essay and On Cause and Effect. For Shepherd and many of her predecessors, necessary connection forms the core of causal relationships, and it is the principle around which most of her critical analysis of other philosophers revolves. Her formulation of necessary connection breaks it down into three kinds: (a) the relation between cause and effect, (b) the relation between effects, and (c) the relations between causes. While (a) and (b) are relations which she explicitly discusses, (c) is a relationship that can only be inferred after she has both differentiated between (a) and (b), and she has prepared the conceptual groundwork of unknown external objects.

The relationship between cause and effect is most easily understood once we take a closer look at how Shepherd defines both while they interact in a causal capacity. We already understand what external and internal objects are, and how these concepts are superimposed over causes and sensible effects respectively. From this we also have a basic understanding of how the two sorts of objects are in relation to each other. But when considered as causes and effects, rather than external and internal objects, we need to revisit Shepherd's definitions to get a better handle on their unique characteristics.

In On Cause and Effect, Shepherd explains that objects, when considered in relation to ourselves, can be considered as masses of qualities. When these masses of qualities mix together with other masses of qualities, that is, undergo a change of some sort, they form new qualities which once exhibited to the senses become sensible effects. These new qualities we call effects in two senses, they are the new masses created by parent objects, and they are sensible effects once imposed on the senses (PWMS 1.46- 
47). External objects in relation to us are internal objects. External objects act

independently of our senses and we witness the combination of various sensible qualities.

This relation is an active causation of sensible experience within us. The sequence of changing qualities we understand as cause and effect, but we must remember that this is

only part of the story. If we recall Shepherd's differentiation of sequence and

synchronicity, we find that,

Cause producing Effect, therefore, under the strict eye of philosophical scrutiny, is a new object exhibiting new qualities; or shortly, the formation of a new mass of qualities. A chain of conjunctions of bodies, of course, occupies time; and is the reason why careless observation...occasions the mistake by which [some] consider subsequency of effect, as a part of the essential definition of that term, and priority, as essential to the nature of Cause.

(PWMS 1.50-51)

The existence of the cause, or mass of qualities, is simultaneous with the qualities which we can observe. It is the individual observed qualities with exhibit themselves sequentially. Here again, as in the earlier discussion of synchronicity, Bolton provides some helpful clarification. Bolton conjectures that Shepherd is presenting a modified version of Aristotelian substance accident ontology, which supposes that qualities depend on substances in an asymmetric way (Bolton, 247). Here, effects, or observable qualities, are affectations. As a result,

They ascribe to, or presuppose, subjects on which they depend in roughly the way figure or motion depends on the existence of a moving or figured body... Qualities necessarily depend in an asymmetric way on the natures, or objects to which they belong; objects do not depend in this way on anything else. Shepherd's innovation is in treating the notion of inherence as a biconditional necessary connection. That is, necessarily if a quality exists, it belongs to a certain object... And necessarily if an object exists, it has each of its several qualities... Accordingly, it is impossible that there should be a merely contingent connection between a cause and its effects.

(Bolton, 247)

The biconditional relationship is a representation of the absolute necessity effects have to inhere in their causes, if certain qualities exist their object must exist, and likewise if the 
object exists so too will its qualities without fail. As Bolton proposes, this sets Shepherd noticeably apart from Aristotle. His understanding of accidents does not allow them to form any sort of relationship of necessity with their substances. For any given substance, take away any of its accidents and its essence will be unaffected. In Shepherd's reformulation, the opposite is true. Narrowing this discussion to focus on how this is exhibited in sensation, sensible effects depend on external objects in order to exist, and as a consequent, if an external object exists, its effects must exist. If for some reason there should be an apple, but we cannot observe its colour, there must be another cause present to inhibit this result. But should an apple be incapable of exhibiting its colour even when under the proper conditions then we are really talking about some other sort of object. The external apple could not fail to exhibit its qualities to us if there were no other cause to inhibit this presentation, thus the presence or absence of certain sensible qualities (when the conditions are determined to be suitable to their expression) determines whether we are talking about one particular external object or another.

This two way necessity between sensible effects and causes brings us back to the earlier claim that they are synchronous. If we were to hold to a traditional antecedence/subsequence account of necessity, this relationship would be logically impossible. This would amount to claiming that effects determine their causes, which under such conditions creates a temporal paradox where things that have not yet happened determine what has already taken place. Synchronous accounts of necessity avoid this temporal paradox because claiming that effects and causes determine each other points only to their coextensive existence and the metaphysical dependence of internal objects on the external objects they reference. Again, internal objects are nothing 
but external objects that have been witnessed by sensation; they literally have no existence without external objects. External objects, when unobserved, may have any conglomeration of unobserved qualities, but when they come into contact with the senses they must exhibit themselves in particular ways.

This necessity is based upon two foundational metaphysical principles which Shepherd sets out early in her essays: first, anything which begins to be necessarily has a cause for its beginning, and second, similar causes have similar effects in similar circumstances. Bolton argues that these principles capture the opposition between Shepherd's view and more established theories, and that this distinction relies for the large part on Shepherd's thesis that anything which begins to exits can be categorized as a quality (Bolton, 248). Shepherd defines a Cause as,

such an action of an object, as shall enable it, in conjunction with another, to form a new nature, capable of exhibiting qualities varying from those of either of the objects unconjoined. This is really to be a producer of new being. - This is a generation, or creation, of qualities not conceived of, antecedently to their existence.

(PWMS 1.63)

Essentially, a cause is the action of an object which is capable of exhibiting qualities. Qualities are dependent upon the objects that exhibit them for their existence and, "that which requires another object for its existence, must be necessarily connected with it," (PWMS 1.64). Thus, an Effect is a property, or quality of its cause, and is necessarily connected to it. This means that external objects as created by other external objects, as well as sensations, as effects are necessarily connected to their causes. As before, this shared trait between internal effects and external effects does not diminish the causal capacity of external objects, because the causal power of internal objects is delimited by their dependence on the senses, not their dependence on their external objects. 
External objects must exist prior to the effects they produce before they can produce them (though in that production they are of course synchronous). Applying the principle of sufficient reason, we see that effects are always in the position of needing an explanation for their existence. No effect can exist prior to its cause, so logically, at some point there was a primary cause. Here Shepherd must present an argument for a first cause, or else admit to an infinite regress of causes. However, neither "solution" will have a bearing on the immediate discussion of necessity. ${ }^{17}$ External objects are still partially inaccessible to us but through this necessity, as discussed in the previous section, some information about them is still accessible because of the necessary relationship they share with their internal objects.

The principle of sufficient reason can also be used to examine the premise that similar causes have similar effects under similar circumstances. We are presented with two circumstances A and B, which are, for now, identical circumstances. Suppose that during both $\mathrm{A}$ and $\mathrm{B}$, we are witness to a particular effect, -for instance, we see an apple. We can, in accordance with the principle under consideration, accurately claim that our witness of the apple has the same or similar causes in each circumstance. If we see the apple one moment, and not the next, then we can infer that some aspect of A or B has changed. Either a cause has been removed or added which accounts for the difference. Each change requires an explanation as mandated by the principle of sufficient reason, a principle which is possible to live up to because of the necessary connection between

\footnotetext{
${ }^{17}$ This is a very interesting topic which Shepherd does address to some extent in both of her major papers, however it is outside of the scope of the current discussion and indeed worthy of its own dedicated investigation. Shepherd's theistic views are presented as challenges to contemporary accounts, and she often accuses other philosophers, like Berkeley, of diminishing the power and perfection of God (even . though they seem to give God a more direct and constant role). Shepherd does seem to have a belief that God is the ultimate cause, however, and I do not believe she was ever challenged publically or academically for being impious or blasphemous in her presentation of causality.
} 
cause and effect. One, these effects cannot begin to be under their own power. Two, the relationship is biconditional in that the presence of the cause necessitates the effect, and the presence of the effect attests to the existence of the cause. If there is a difference between effects there must be something to account for it. Likewise the similarity between effects demands the presence of like causes or else there would be nothing to account for the similarity. Bolton explains that

One might think that this is an application of the principle of sufficient reason; there is no difference between similar instances without a sufficient reason. But although this is correct, sufficient reason applies in the domain of cause, effect, or things that begin to exist, only because causes metaphysically determine effects. The principle of sufficient reason is not a premise from which it is supposed to follow that everything that begins to exist has a cause; on the contrary, the applicability of sufficient reason follows from [the principle that necessarily everything which begins to exist has a cause]. To put it differently, causal generalization is metaphysically underwritten by the necessary relation between cause and effect in general"

(Bolton, 251)

Bolton is trying to explain that we are not using the principle of sufficient reason to justify causal principles, but rather that the principle is applicable only because there is a relationship of necessity between causes and effects. The intimate relationship of necessity between them has two corollaries: first, there is a relationship of necessity between effects, and second, there is a relationship of necessity between causes.

I begin with the first claim: that effects are bound together in a relationship of necessity (a claim which Shepherd openly acknowledges). The relation between effects does not take the same shape as the bond formed between causes and effects, but it is a direct and natural result of that relationship.

Because we experience things in time, effects appear to us in sequence. Since effects are bound to their causes, the sequence of effects binds each effect to those that precede and follow it. This is not a direct causal necessity (like causes and effects), in that 
each successive effect depends on its predecessor. Instead, it is a necessity formed by their shared references to their concomitant causes, and while not identical to causal necessity is still defined by it. As Bolton writes, "the sequence of events is thus bound by causal necessity even though causes are temporally coextensive with their effects. Shepherd accordingly distinguishes between two sorts of necessary connections:" (Bolton, 252) the necessary connection between cause and effect, and the necessary connection of invariable sequences of effects. The invariableness of sequence seems strikingly close to Brown's proposal of invariable priority, and in many ways what Shepherd is proposing for internal objects is similar. Where she and Brown differ is in the epistemological authority given to invariableness when seeking epistemic justification for causal belief, as well as the delegation of this sequence to the realm of effects rather than a causal chain.

Shepherd explains that, "the antecedency and subsequencey of certain respective aggregates of sensible qualities, must necessarily be INVARIABLE in like circumstances ; for they are successive and similar effects, from successive and similar causes, instead of the succession itself forming essential cause and effect," (PWMS 2.129) as Brown insists it does. If Shepherd were to hold succession as something essential to cause and effect, she would be unable to make any claims about the two kinds of necessity she proposes because we would inevitably be unable to find any necessity between the events we witness, as Hume warns us.

As a result of her difference from Brown, Shepherd is able to make strong broad arguments about the relations between causes and effects. We can clearly see how 
cause/effect and effect/effect relations are dissimilar, yet are necessarily related concepts because of the phenomena they describe. Shepherd states that,

Necessary connection therefore of cause and effect, arises from the obligation, that like qualities should arise from the junction, separation, admixture, \&c. of like aggregates of external qualities. But the necessary connection of invariable antecedency and subsequency of successive aggregates of sensible qualities, arises from the necessity there is, that there should be invariable sequences of effects, when one common cause (or exterior object) mixes successively with different organs of sense, or various parts of the human frame, \&c.

(PWMS 2.131)

The connection between effects and between causes and effects is evident in this passage.

A last kind of necessary connection, which is not presented in Shepherd's definition, or in Bolton's assessments, is hinted at here: the connection between causes. Part of this reticence is a result of the difficulty in forming arguments about the nature of external objects, and part is also due to the way in which Shepherd defines causes and their power to act as such. On one hand, to propose a relationship of necessity between causes implies that there is some sort of interaction between them. Earlier, we found that interaction between external objects poses a potential problem for Shepherd's metaphysical representation of them. However, we may be able to resolve some of that tension if we model the discussion of necessity between causes after the one she presents on effects. Harkening back to the argument that it all things which begin to be have a cause and applying the principle of sufficient reason will allow us to explore the relationship between causes.

Causes, like sensible effects, warrant explanation for their existence, especially if Shepherd insists that external objects are masses of qualities which interact with each other. This explanatory need arises from the fact that internal objects represent actual phenomena and have real reference to external objects. As such, internal objects must 
also represent actual relationships between external objects. Even if we cannot give an accurate name to a set of external objects, we know that when the effects happen in a certain sequence, so too must the order of their concomitant causes. Almost like a mirror of the necessity between effects, there is a relation built between causes, and sequences of causes.

Causes cannot be related to causes like they are to effects. This would be the same as claiming that the sequence of causes defines necessary connection, which is the exact same problem that Shepherd sees in the misinterpretation of sequences of effects, simply stated from the side of causes. Although causes do not relate to each other in a perfect simulacrum of the invariable sequence shared by effects, they do share the characteristic of being related to each other because of the effects they are necessarily related to. The perfection of similarity is stopped in two different ways. First, when considering sensible effects, since they have no power to act as causes their absolute dependence on external factors is not precisely mirrored by causes. Second, when considering effects in general, while they share a biconditional relation of necessity with causes because of the synchronicity of causation, as discussed before, this does not mean they have the power to determine anything about their causes. For effects, the invariableness of their sequence is constructed by their dependence on causes. Causes arguably act in sequence, but the invariableness of the sequence of causes cannot be determined by effects, only discovered by it. That is to say, that while we know effects are determined by causes, causes too must interact in specific ways to bring about their effects. Thus causes are necessarily related to each other, not invariably, but conditionally, in the condition that certain effects are witnesses so to do certain causes share a common space and time. The 
precise principles of this relationship are purely inferential in that we can only reason from experience about the particular causes in relation to each other. However there is a general principle between causes as a whole that we can safely claim, which is this common circumstance they share. This does not mean the relationship is circumstantial, as in contingent, but based on time, place and a variety of other conditions. The sequence of their combination is inconsequential, but their existence and the fact that they interact is the relation of necessity they share. The relation of necessity is built upon a common existential or phenomenological ground: the space in which they operate and exist.

Although it is difficult to assess the nature of the relationship between external objects as causes, I believe that this cause/cause relationship is an unavoidable consequence of Shepherd's other principles of necessary connection. This relationship might pose problems for how we understand the independence and power of causes, but it seems to be in line with the invariable sequence she proposes between effects, and the synchronicity they share with causes. Shepherd believes that internal objects provide an actual and reliable reference to external objects. As such there is some reason to think that if the internal object of redness is a real quality of the external world, then the relation of necessity between effects is mirrored by some sort of relation of necessity between causes also.

The importance of addressing the three types of necessary connection is that they give us a general principle by which we can acquire and gauge all particular occasions of cause and effect. The necessity Shepherd proposes says nothing about the specific causal relations in any given circumstance, but she does provide us with a rule which we can 
apply in all instances where we wish to discover causal relations. She believes this

general principle is much more useful than specific causal knowledge. This is because,

the doctrine of necessary connection is the result of perceiving that two or more individual objects, or quantities, which are like each other, are to all intents and purposes with respect to any relations which may arise respecting them, identically the same, and may be always considered as the same individual object or qualities repeated as many times: instead of as many various although similar objects. It is such a perception as this, in which consists the essential power of abstraction: an abstraction which Bacon, Newton, Berkeley, all must have allowed, or there could have been no science.

(PWMS 2.286-287)

This sort of necessary connection is strong enough and broad enough to give us access to the whole variety of relations between causes and effects, while at the same time allowing us to explore any particular one of these events in great detail. Bolton contrasts this with Hume's theory of necessary connection. She states that for Hume, necessity must be

perceived anew in each particular instance. Still, if we had sense impressions of causal necessity of the sort Hume apparently seeks, then we would be presented with a necessary bond between two particular objects; we would understand why and how it is forged. This is more than Shepherd can claim. For her, we establish necessity by considering the abstract cause-effect relation, and thereby prove it in general. This leaves us without insight into the nature of workings of this or that specific necessity.

(Bolton, 257)

This lack of specific knowledge about a given necessity is only a problem if we believe

that we can only arrive at the general principle from abstractions on the specific knowledge. The necessity that Hume proposes can only be reached through repetitive experience as a result of skepticism about causal necessity in general. Meanwhile, Brown's insistence on the essential nature of invariable sequence renders general causal principles arbitrary in its own way. Although it does propose some causal necessity, of the kind between effects, it is a rather superficial sort of necessity that focuses only on particular cases of cause and effect and cannot give us deeper insight into the inner 
workings of the universe, Shepherd argues. It simply states that something must be the case because it is the case and has always been thus.

Shepherd challenges these skeptical and superficial accounts of causation, stating

that,

causation is necessary not arbitrary ; and though the nature of any particular effect requires to be ascertained by experience, yet it is reason must show its necessary connection with its cause, as opposed to its arbitrary or accidental connection with it; its immediate inherence in its cause, as opposed to its mere subsequency to it; and the knowledge of its invariability of connection for the future, as opposed to the mere experience of its conjunction in past time. Thus although experience is required to show [particular causes are related to particular effects], the aid of reason is also equally needful, yet sufficient to show, that the connection between [such particulars] is necessary and invariable.

(PWMS 2.294-295)

Here she is building up necessity as the principle of causation reached by the combined

efforts of both the faculty of sensation and the faculty of reason. This principle will be the main tool by which we start building justification for our beliefs about particular causal relations. She believes that the epistemic justification for the principle of necessity itself will come directly from our faculty of sensation. This is naturally a point of contention between Hume, Berkeley, Brown and herself, as they each have diverse theories regarding perception and justification for belief.

\subsection{From Necessity to Sensation}

Necessity and synchronicity form the very heart of Shepherd's causal theory. The necessary connection between causes and effects is due to their inseparability during the moment of causation. By providing a general theory of causality, Shepherd gives us a tool by which we can assess all of the particular instances of causation we experience. The errors she finds in other theories of causation most often stem from their focus on these particular cases rather than a general principle. Sometimes this is because of how 
they interpret sequence, but other times this is because they do not place any faith in the epistemic means by which we acquire knowledge of these relationships.

Shepherd's theory is not without its own concerns. Reconciling ourselves to an account of invariable sequence between cause and effect is not an easy task, especially when Shepherd consistently offers warning of the easy trap this presents for theories of causality. By symmetry we can suppose that causes share a relationship of necessity, as do effects with each other, and with causes, but this does not mean that it is an easy association. Now, however, we can start analysing Shepherd's epistemology in order to discover how she frames perceptual experience and both how and where we find justification for our belief in necessary connection. Her principles of sensation are informed by the theory of necessity as well as the objects that have these relationships. As well, sensation (the act) will share some of these characteristics and she believes, as a result, our ideas and the justification for our beliefs both come directly from the faculty of sensation itself. 


\section{Chapter: The Faculty of Sensation}

\subsection{Sensation, Perception, and the Search for Epistemic Justification of Belief}

In the evaluation of the truth of knowledge, theories about how we engage with the world form an essential part of determining not only the sources of our experience, but the validity of claims made upon them. In some accounts, sensation and perception are terms used interchangeably to describe the faculty which is associated with experience, but Shepherd, like Locke and Berkeley, disparages this interchangeability, believing that sensation and perception are terms which give reference to very different ideas. She explains that,

I mean to follow the example of Dr. Berkeley in the use of the word sensation chiefly, instead of perception; because it is a generic term, comprehending every consciousness whatever...although every sensation may not be the perception of an exterior object, acting on either of the five organs of sense, yet there can be no perception of such objects without that inward act of consciousness, Which, as a consciousness, is in truth a sensation of the mind.

(PWMS 2.6-7)

Her division between sensation and perception will lead to the claim that all

consciousness should be considered under the category of sensation, as was touched upon in chapter one (PWMS 2.135-136). Perceptions then, can be understood as the sensation of sensible qualities presented by external objects. Shepherd recognizes the creative power of minds, and accordingly ideas. This division between perception and sensation serves to separate the internal objects we receive from the organs of sense and those we receive from the mind. Differentiating this ensures that we do not make the confused claim that ideas are perceived by the organs of sense (as per her challenge against Berkeley's equivocation, PWMS 2.198-200). It is important to keep her meaning clear between sensation and perception when discussing sensation as a faculty, since other 
philosophers do not always make such a distinction. The theories of perception presented by Hume Berkeley and Brown, which will be examined in comparison to Shepherd's, each present a unique view of how perception and sensation work.

The nature of external and internal objects has shed some light on how Shepherd frames sensation -it operates as a combination of sense and reason, as a combination of experience and rationalizations about the relations between objects- but these definitions still leave us with questions about the nature of sensation in general and how we find justification for our beliefs in causal principles. Shepherd presents a metaphysical account of causation which shares interesting characteristics with her metaphysical understanding of sensation. There is a necessity implicit in sensation which, while not causal, underwrites knowledge formation and is also the reason why we can believe in the veracity of these judgements. Under her account, the very act of sensation is intimately tied to knowledge formation in such a way that while we can make errors about the particular relationships we suppose to exist between objects, the general causal principles are guaranteed to us upon our first experience of change. ${ }^{18}$

Ultimately, for Shepherd, sensation is our ability to take in information about the world and make judgements about the relationship we recognize within it. As such, distinguishing between the "false" notions of cause discussed earlier and her version is not just about telling a more accurate causal story, it is also about discovering how the sensation and the understanding operate and how we actually achieve and justify causal knowledge. While synchronicity presents a relation that is not initially as simple to grasp as a relationship based on sequence, in her opinion it is a much accurate way to account

\footnotetext{
${ }^{18}$ As opposed to Hume, who believes we can only form such beliefs after repeated experience.
} 
for knowledge acquisition. In a loose sense we lose the "direct" evidence of causation which sequence models suppose, but in exchange Shepherd's model defines a single group of phenomena which provide us with evidence of a continuous and independent external world and the general principles by which we can evaluate the relationships within it.

Shepherd believes that this kind of evidence is more valuable than sequential evidence because it provides proof of the general principles of causality she seeks to establish rather than focusing on the specific nature of particular relationships. It also allows us to overcome some of the problems for causal theories that philosophers like Hume bring up about reason, the understanding, and logic - such as acknowledging the weak links between sequenced events, - that would prevent us from gathering true causal knowledge about the world if we were to follow these other accounts. Unlike Hume and Brown, Shepherd believes that our sensation of the world around us is the source of causal knowledge. This knowledge is not based on a priori intuitions ${ }^{19}$, or inferential reasoning or any sort of reason alone. Instead, it is grounded in a combination of our sensed qualities and the relationships that reason recognizes between them that grant us immediate knowledge of the general causal principles which govern the world.

This is a heady claim, one which stands in opposition to a long tradition of sequential accounts of causation, intuitionist models of perception, and framework models of perception. Framework models propose that there are certain elements of

\footnotetext{
${ }^{19}$ I specifically mention a priori intuitions here, but Shepherd also has issue with intuition in general. By intuition it is meant any immediately grasped concept, with or without the aid of experience. Shepherd does make the statement that we come to an immediate realization of causal principles, but under her account, as the discussion which follows will attempt to show, the process of sensation is too complex and involves both internal and external input, such that to call this immediate grasp of causal truth intuition is to misuse the term and oversimplify the process.
} 
perception or sensation which are provided by the mind that help shape experience.

Shepherd indicates that she believes these elements such models propose are similar in many ways to intuitions and instincts, and represent natural tendencies for sensation to be framed in a specific way. Frameworks, intuitions, and instincts alike, all pose problems for the complex picture of sensation she wishes to present, because they either simplify the process or confuse the sources of the content of our knowledge.

In order to gain a better understanding of Shepherd's theory of sensation and epistemic justification for causal belief, it is helpful to first examine the composite parts of sensation, an abstraction on Shepherd's theory proposed by Martha Brandt Bolton, or as she names them: the intentional and aetiological content of sensation ${ }^{20}$. Finally, it will be important to discuss why Shepherd's theory of sensation does not fit within a framework model of perception. Examining all of these aspects will illuminate her explanation of our acquisition of causal knowledge and knowledge of necessity, and why our belief in the truth of this knowledge is epistemically justified.

\subsection{Hume and the Habit of Imagination}

In the beginning of A Treatise of Human Nature, Hume sets out to define the various objects of perception with the aim of creating a "science of the mind", and as a part of that project, explores how we arrive at ideas of necessary connection, and eventually causation. He explains that,

All the perceptions of the human mind resolve themselves into two distinct kinds, which I shall call Impressions and Ideas. The difference betwixt these consists in the degrees of force and liveliness with which they strike upon the mind, and make their way into our thought or consciousness. Those perceptions, which enter

\footnotetext{
${ }^{20}$ I will adopt these terms from Bolton for use in this paper, as they currently provide the most concise way to reference these ideas without needing to synthesize a new and inevitably redundant set of terms, simply for their own sake.
} 
with the most force and violence, we may name impressions; and under this name I comprehend all our sensations, passions, emotions, as they make their first appearance in the soul. By ideas I mean the faint images of these in thinking and reasoning...

(Hume 1928, 1)

Impressions fulfil a similar role to Shepherd's sensations, in so far as both include emotions, physical sensations, and anything generally associated with conscious sensory experience. Ideas for Hume, are the next level of mental involvement, they are formed of impressions which have either been processed through reason or imagination. Ideas and impressions are related to one another, as all ideas are copies of impressions. While this is guaranteed of simple ideas and impressions, it is incorrect to assume that complex ideas are copies of complex impressions, as some of our complex ideas have no impressions associated with them, and many of our complex impressions can never be accurately represented by ideas (Hume 1928, 2-3). These complex ideas depend on the simple impressions that form their composite nature, but there is not a one for one correspondence between a complex idea and an impression.

Hume believes that there is indeed a connection between simple ideas and simple impressions. He states that, "All our simple ideas in their first appearance are deriv'd from simple impressions, which are correspondent to them, and which they exactly represent," (Hume 1928, 4). This almost sounds like the relationship between Shepherd's external and internal objects, in that internal objects resemble external objects, but that is where the similarity ends. The relationship he is describing is not between internal and external objects; it is completely internal, or dependent on human experience. Our impressions, so long as they are simple, are the subject of the simple ideas which represent them. Without some sort of impression, these simple ideas would have nothing to reference. We must now look more closely at how ideas relate to one another in order 
to determine the impression(s) from which we form the idea of the of necessary connection.

As an idea of a relation, necessary connection cannot be understood in the context of impressions alone, for it is an idea of a relation between ideas, like contiguity and resemblance, and like them is not merely concerned with the relation between impressions. Hume explains that,

were ideas loose and unconnected, chance alone wou'd join them; and 'tis impossible the same simple ideas should fall regularly into complex ones (as they commonly do) without some bond of union among them, some associating quality, but which one idea naturally introduces another. This uniting principle is not to be consider'd as an inseparable connexion...the qualities, from which this association arises, and by which the mind is after this manner convey' $\mathrm{d}$ from one idea to another, are three, viz. Resemblance, Contiguity in time or place, and Cause and Effect.

(Hume 1928, 10-11) Resemblance is the association of objects found to have similar characteristics, and is an easy association for the mind to reach simply because of the immediacy of the comparison between objects of sense or memory. An example would be the experience of two red objects, or of doors of the same size, even the pain caused by stubbing a toe in two different instances. Contiguity, which is the association of objects on the ground of similar place and circumstance, requires more habitual experience to arrive at, but is also fairly accessible as an association of the mind. Snow and leafless trees, or a memory of a person and the sentiment felt towards them are considered contiguous because they occupy the same circumstances as each other. Cause and effect is the belief that one object is responsible for the presences of another, and seems to be the strongest association we form in our imagination. The movement of one billiard ball being responsible for the movement of another or a memory of some sadness renewing that feeling within us are examples of such a relation. It makes it easy to recall one idea from 
another, but this association requires further examination since it is not all that clear that it is actually a simple association like resemblance and contiguity. The primary notion included in the idea of cause and effect is that of necessary connection (Hume 1928, 11). This idea of necessary connection is supposedly a simple one, so if we wish to find evidence for it, there must be some simple impression of which it is a copy. Thus in order to make sense of it, we must find an impression from which necessary connection is derived (Hume 1928, 11-15).

We suppose that this impression comes from the relationship we find between objects which are causes and their effects, but this relationship is not easily or immediately determined, according to Hume. We can immediately recognize their contiguity in space and time, and that one precedes another. We also recognize when there is a similarity between objects, such as the coldness shared by a glass of water and the ice which resides in it, but there is nothing more that can be gained from this without introducing complex ideas. After repeated cases of these objects following each other, we become accustomed to their association and find that a certain object is usually attended by another. This is the impression which gets us an idea of necessity, but it is clearly a complex idea requiring the advanced operations of imagination and memory to form its inferences (Hume 1928, 155-172). This idea is something concocted by the imagination, and through reason we can equally prove that this idea both does and does not represent a real relationship between objects. Thus we are no closer to making a determination as to the truth of our beliefs in causal relationships between external objects.

As a method of association by the mind, cause and effect is a relational idea and made of the complex ideas of causes and effects, and it cannot show us anything more 
than what the associations of resemblance and contiguity do with the aid of the imagination. All apparent relations of cause and effect are built on this notion of necessity, but this relation proves to be a synthesis of resemblance, contiguity, and memory, rather than something derived from simple impressions and thus more easily believed to be a true relation in the external world. Anything which is associated causally is so only because the objects share a relation in space and time and through habit we recognize their resemblance to one another, both as a similarity of objects and circumstance. This can give us no true knowledge of causal power, for as we saw in chapter two, Hume argues that sequence is not enough to grant a necessary connection. In a sequential account of causality it is possible that the ideas of cause and an effect can be separated conceptually and thus also in reality without this creating any logical contradictions. ${ }^{21}$ The only justification we have for the inferences we make about causation is that through repeated experience we form a notion of the connection of certain objects and events in our imagination as they appear to resemble each other and share circumstances.

\subsection{Berkeley's Idealist Epistemology}

The category of ideas is different for Berkeley than for Hume, though it is possible that this marks only a difference in terminology, as Berkeley uses "ideas" in the general sense, much like Hume uses the term "perception". For Berkeley, ideas are the "raw" data of sensation rather than the result of impressions being processed by the mind. As an Idealist, Berkeley's metaphysics relies on a strong concept of sensation in order to develop a framework for both the existence of and our interaction with an external world.

\footnotetext{
${ }^{21}$ Hume argues that these concepts can be separated on a conceptual and thus a real level in An Enquiry Concerning Human Understanding, 48.
} 
Ideas, by definition, depend on minds for their existence. The only way we can come to know ideas which are external to, that is not caused by, our own minds is through perceiving them. He explains that,

that neither our thoughts, nor passions, nor ideas formed by the imagination, exist without the mind, is what everybody will allow. And it seems no less evident that the various sensations or ideas imprinted on the sense, however blended or combined together (that is, whatever objects they compose) cannot exist otherwise than in a mind perceiving them. I think an intuitive knowledge may be obtained of this, by anyone that shall attend to what is meant by the term exist when applied to sensible things.

(Berkeley, 25)

When we consider the idea of existence as it applies to sensible objects, we immediately realize that they must exist in a mind. This "intuition" is not an intuition in the sense that it is arrived at a priori, but more of an immediate realization of the consequences of what it means to exist as a sensible object. We intuit that these objects are dependent on minds in order to exist because they are ideas, and ideas cannot exist otherwise. Berkeley's sensible objects are not unlike Shepherd's internal objects, which as sensations have no existence independent of the mind. Where Shepherd and Berkeley differ is in whether these objects represent external objects. For Berkeley, although particular sensible objects (ideas) may have existence independent of our minds, no object may exist independent of minds in general. For Shepherd, as I have shown, external objects exist independently of all minds.

The only things which have actual substance, that is, actually exist independently of perception, are the very things which perceive, or in Berkeley's words, spirits (Berkeley, 26-27). He supports this notion by examining sensation in the Dialogues, in which he seeks to show that sensation is not composed of external and internal content. This is in direct contrast to Shepherd, who believes sensation is made of both our 
sensations, as caused by the external world, and our ability to make rational judgments about the relations between these sensations, the particulars of her view will be addressed shortly.

In chapter one we examined the Dialogues and found that Berkeley believes the combination of external input and an active faculty of the mind during sensation is an absurdity. If we claim that sensation grounded in an active power of the mind and some external content from the object itself we are in error. The mind is not active in sensation, by his reckoning, as it has no ability to will its sensations. If this component of sensation is not present, we are left claiming that the contents of sensation are external to the mind, which is the same as claiming that ideas do not need to exist in minds at all (Berkeley, 133-136). Additionally, since sensation is a passive capacity, there must be something which produces these ideas within us, since we cannot do it ourselves. He explains that,

The ideas imprinted on [my senses] are not creatures of my will. There is therefore some other will or spirit that produces them. The ideas of sense are more strong, lively, and distinct than those of the imagination; they have likewise a steadiness, order, and coherence, and are not excited at random... but in a regular train or series, the admirable connexion whereof sufficiently testifies the wisdom and benevolence of its Author. Now the set rules or established methods, wherein the mind we depend on existed in us the ideas of sense, are called the Laws of Nature: and these we learn by experience, which teaches us that such and such ideas are attended with such and such other ideas, in the ordinary course of things.

(Berkeley, 36)

While Shepherd believes that external objects are the source of our sensory perceptions,

Berkeley believes that these ideas are imprinted on the senses by some other spirit. Since spirit is the only thing which has substance because of its mind-independence, it is the only thing with the power to cause those sensations within us. While other human or animal spirits might be considered to cause some of these ideas of sense, ultimately God is the only being with the power to produce these ideas within us. The orderliness and 
coherence of the ideas of sense attest to the benevolence of God. Through experience we learn of the operations of nature. Rather than being simply a product of habit and imagination (something which we suppose, through appearance, to be the case), we learn of the actual Laws of Nature. Our intuition tells us that for something to exist as an idea it is perceived, and since the ideas of sense do not originate within us they must come from something else. Through God they persist as was shown in chapter one, but through God they are also impressed upon us. Our experience belies that there are relations between these ideas, and the orderly nature we perceive them to exhibit is not an illusion. While this connection may not be necessary connection per se, their regularity can be counted on as one of the laws of nature because they are grounded the benevolent will of God and His desire to create within us an accurate idea of the world.

\subsection{Brown on Intuition and Invariable Antecedence}

Brown's theory of perception incorporates both impressions, in the Humean sense and intuition, which Brown characterizes as something akin to instinct. It is heavily influenced by his belief that intuition informs us about the invariable priority of causes. For him, perception is a "power" of the mind to take sensations and form them into ideas which represent external things. He explains that,

The perception, in short, in smell, taste, hearing, is a sensation suggesting, by association, the notion of some extended and resisting substance, fragrant, sapid, vibratory, - a notion which smell alone, taste alone, hearing alone, never could have afforded; but which, when once received from any other source, may be suggested by these as readily as any other associate feeling that has frequently coexisted with them.

(Brown 1851, Lecture XXVI, 162) The various senses work together to produce a collection of perceptions, none of which alone are enough to give us an idea of an extended object, but in combination are able to grant us an idea of any object we come into contact with. Perception itself is a complex 
process that takes raw sensation and turns it into basic ideas which we are then able to work with on a more complex and rational level. This is not dissimilar to the division which Hume proposes between impressions and ideas, with Brown's sensations taking the place of impressions, and perception occupying some place close to the formation of ideas from said impressions. The difference for him is that perception is no different from any other consciousness of the mind, where for Hume the formation of impressions and the formations of ideas from impressions indicate two different capacities of the mind.

Brown explains that, "the process of perception... implies no peculiar power, but only common sensation, with associations and inferences of precisely the same kind as those which are continually taking place in all our reasoning and trains of thought," (Brown 1851, Lecture $X X V I, 162$ ). Thus there is nothing which marks perception as a unique faculty distinct from reason or imagination, as Hume does, for example; perception is simply another process which forms associations and inferences between its subject matter.

Expressing the similarity between perception and other faculties of the mind is important to Brown because he understands that consciousness, like everything else, is constantly in motion (Brown 2010, 46). To suppose that consciousness is separate from sensation is the same as proposing two simultaneous states of consciousness, which he believes is absurd. This is akin to giving a category of objects its own particular existence, such as claiming there is some beast known as a quadruped which is separable from all the animals which are in that category (Brown 1851, Lecture XI, 68). Ultimately, he believes that consciousness is not a distinct power of the mind, but is the general term under which all of our states of mind, including sensation, are understood (Brown 1851, 
Lecture XI, 70-71). So perception is naturally similar to how we conceive the other mental processes, it is our term for consciousness which deals specifically with sensation, unlike reason, for example, which is our term for consciousness when it deals with ideas of relation.

Our knowledge of cause and effect then is derived through our perception of various sensations which give us the impression of the relation between objects. Brown believes, "we had no other impression of relation than of a priority and subsequence that were limited to that particular moment...," (Brown 2010, 47). Our first impressions of any particular moment of causation only ever grant us the sensations of sequence and priority. Moving from these impressions to a concept of causation and necessary connection is not easy, for as with Hume, the difficulty lies in proving an actual necessary connection between objects based on sequence alone.

Brown argues that we can extrapolate from our experiences that the relation between causes and effects is an impression which we receive upon our very first experience of the world. We form knowledge of causal necessity very early in our experience, for Brown explains that, "as far back as our memory reaches to the earliest events, that occupied us either actively or passively in childhood, we do not remember a time, in which the belief of some permanent relation of this kind was not immediate on the observation of change," (Brown 2010,65). This knowledge is not gained through habit, as Hume proposes, but is rather something which we arrive at intuitively. Neither speculation on observation from one nor from many phenomena, when we attempt to do so in a way which is abstract from intuition, is enough to give us any insight into the unobservable workings of nature. Hume agrees with this claim, but Brown further 
believes that while custom can only grant us knowledge of past change, "the belief of Power is the belief of changes that are to be" (Brown 2010, 67). Power, as Brown understands it is the invariable priority of causes. In other words then, our intuitive belief in the notion of power recognizes something essential and necessary about the sequence of causes, and this allows us to make accurate statements about future change. We cannot find any evidence of power from simply remembering what we have experienced in the past; it is a knowledge that is arrived at through our immediate experience of the world and our intuitions about the relationships that form between objects. Brown states that,

the belief of regularity of sequence is so much the result of an original principle of the mind, that it arises constantly, on the observation of change, whatever the observed antecedents and consequents may have been, and requires the whole counteracting influence of our past knowledge, to save us from the mistakes into which we should thus, at every moment, be in danger of falling.

(Brown 2010,68)

Experience and habit are only strong enough to grant us knowledge of the sequence of

past causes and effects. If we want to work toward an understanding of future sequence we must rely on an original principle of the mind.

Just so,

It is not to experience alone, then, that we must have recourse for the origin of the belief, but some other principle which converts the simple facts of experience into a general expectation or confidence, that is afterwards to be physically the guide of all our plans and actions. This principle, since it cannot be derived from experience itself, which relates to only the past, must be an original principle of our nature.

(Brown 1851, Lecture VI, 34)

This is not some mysterious sort of intuition, as he feels the term is commonly used to imply, but rather more of an instinct, a natural tendency for our minds to perceive such relations between objects. We are justified in the claims we make based on this instinctive understanding, both because it is a naturally ingrained instinct, and because of Divine providence. The necessity we perceive between causes and effects must take the 
form of invariable sequence, as we discovered when we examined Brown's notion of necessity in chapter two, since there is nothing which denotes the power of an object to act as cause, except for its invariable priority. Its truth is granted through our God-given intuition that causes always invariably precede their effects.

Brown believes that, because of this divinely granted and instinctual belief, it is our faith itself, which, in a great measure, makes the surrounding objects what they truly are to us, by rendering permanent, in our voluntary use of them, what otherwise might have seemed to pass away, in the moment in which we had chance to be under their influence. It is not to science only, then, but to all the practical arts of life, and consequently to the preservation of life itself, that the faith is essential, which converts the passing sequence of phenomena into signs of future corresponding sequence.

(Brown 2010, 48)

This faith is a devotional or religious faith, not simply trusting in our own abilities. It is a faith in God's wisdom and benevolence, and is the ultimate source of and justification of our rational belief. This faith grants us several facts, one of which is the assurance that there are really existing objects in the world, and they are capable of affecting us. This fact assures us that our understanding of the world is accurate. Brown explains that,

it is by affecting us, that [objects] are known to us; and, if they were incapable of affecting us, or -which is the same thing-if we were unsusceptible of any change on their presence, it would be in vain, that the gracious benevolence which had surrounded us with them, provided and decorated for us the splendid home in which it has called us to dwell.

(Brown 2010, 54)

Brown sees it as impossible that God would not create a world in which we are actually

affected by the things around us, as our impressions lead us to believe, as this would render the benevolence and perfection of God and the world he created superfluous.

\subsection{The Aetiological and Intentional Content of Sensation}

Shepherd generally warns against using sequence to discuss cause and effect, thus Brown's heavy insistence on priority causes her great concern. Although sequence is an 
undeniable part of the relationship between causes and effects, because both causes and effects exist in time, and we experience sensible effects in sequence, it all too often becomes the only factor that philosophers use to define this relationship. Bolton argues that this tendency arises because of a confusion of what she calls the intentional and aetiological content of sense perception. She coins these terms based upon Shepherd's description of the perception of continuously existing external objects as "an affair of the understanding" in which our minds compare previous notions to our sensations as they occur (PWMS 2.168-169). Bolton's definitions are also informed by Shepherd's claim that "the ideas of reason must be the corollaries included in the impressions of sense," (PWMS 2.224). Shepherd's statements will be attended to shortly, but for now, analysing Bolton's term will be more helpful for understanding the two sources of content within sensation.

Internal objects, as Bolton describes them, are made up of input from two sources. The aetiological content of sensation is that content which is given to us by external objects. It is the material which gives direct and unadulterated evidence of the qualities that external objects exhibit to us. Intentional content, on the other hand, is the part of sensation which is added by the human mind from the faculty of reason. All sensation then is made up of both the qualities we sense and the relations that we recognize between them or between them and external objects in the reasoning.

Bolton believes that Shepherd is right to challenge the traditional sequential characterization of causal relationships because the use of antecedence and subsequence to describe causal relations ignores important both how different kinds of objects relate to 
each other and misrepresents the aetiological and intentional content of perception.

Bolton explains that,

if there is any attribute of a cause by which it might be thought to determine an effect, it exists during precisely the same interval as the cause itself; a nonexistent thing has no attributes. Defining a cause partly in terms of an event temporally antecedent to its effect precludes the possibility of a genuinely necessary connection between them. For similar reasons, it undermines the efficacy of causes. If the proximate cause produces its effect at all, it does so only during the time the cause endures; it cannot act efficaciously when it no longer exists.

(Bolton 244)

Bolton is emphasizing the intimate connection between the notions synchronicity, causation, necessary connection, and the ability of an object to act as cause, and presents a good synthesis of Shepherd's theory of causation. While a metaphysical concern, undermining the efficacy of cause is detrimental to sensation because sensations are absolutely dependent on causes for their existence. An object cannot have any causal power before it begins to exist or after it ceases to exist. It is part of Shepherd's description of a cause that it must exist antecedent to any effects it brings about, but this does not define the whole character of a cause (PWMS 1.49-50). This is important to sensation because it is the reason why Shepherd feels justified in claiming that reason can get us causal knowledge on the first experience of change, without the need for habit. Since external object exist synchronously with their sensible effects, and the aetiological and intentional content of perception are combined in the act of sensation, our rational judgements about the world are immediate and represent actual relations within the world. The combination of aetiological and intentional content during sensation is where the external and internal world come together in the understanding and allow our internal dependent faculties to interpret the external world. Without this combination it is challenging to account for how we are capable of perceiving the physical world mentally 
and are capable of making judgements about it. The success of Shepherd's theory to account for mind/body interaction depends on this definition of sensation as a joint process of the mind and the senses, and the credibility we give to such an account.

One challenge to this understanding of sensation is that memory poses a problem for our knowledge of causation on the grounds that an object has an effect on us long after is has been presented to the senses, and in some cases faded from existence entirely. This would pose a challenge for the principle of continuity and potentially undermine synchronicity, which would in turn jeopardize the veracity of our judgments during sensation. Despite its initial appeal as a critique, since it would mean that objects and our sensation could possibly be separated and thus the aetiological content no longer directly accounted for, this is an incorrect assessment of the process of memory and sensation and can be easily answered when we remember that the mind too has causal power. The mind is actually an external object independent of sensation in its own right. Memories of objects and even hallucinations or dreams can exist independent of the object which they resemble, but they are images created by the workings of the mind and depend on it as their cause. They are not independent of their true proximate cause, but are mistaken as such because they bear resemblance to previously experienced sensations. Ideas, including memories, are the internal representations of the qualities or states of the mind. This is my interpretation of the implications of Shepherd's theory, but it is strongly supported by her statement that,

Inward thoughts are also beings, which when not thought of, and not contained in any given state of the mind, are nought; but continually existing causes, ready to appear, upon the application of the organs of sense, efficient to the production of certain sensations in particular, when operating upon the capacity for sensation in general, are out of, and distinct from, that is to say, not included in that capacity.

(PWMS 2.43-44) 
This is why it is so important to keep the distinction between perception and sensation straight. While we cannot be said to perceive ideas, or various other mental phenomenon, we can indeed sense them, hence her inclusion of memory, emotion, and other such mental activities under the category of sensation. Though ideas may be a different kind of quality than the ones we perceive from other external and physical objects, they are no different from the qualities of the apple we see before us when we consider them on a causal level.

The "challenge of memory" is not unlike the trouble which sequence presents for necessary connection. Both are directly related to our incorrect attributions of certain experienced events as causes rather than sensations. When dealing with sequence we typically either confuse effects for causes, and then the only thing that can connect causes and effects is the sequence in which they occur, or else we take antecedence to be the primary attribute of cause, and allow it to define the relationship between causes and effect, which weakens arguments for necessary connection. As we saw earlier, Bolton believes this is to mistake sensible effects for causes (Bolton, 244). But realizing that the act of conjoining the fire and $\log$, not the fire and $\log$ which we witness, is the cause of combustion, we will realize that our sensations of fire and log are the internal representations of external objects. Our sensation of the resulting combustion is the internal representation of a change taking place between the natures of the fire and the log. Neither sensation is necessarily connected to the other as causes are to effects, but they are necessarily connected through their relationship to their external cause, as we know from our examination of necessary connection. Both sensations are experienced in sequence, yet this sequence points only to the existence of the fire and log before their 
interaction and the resulting combustion. Each sensation can be seen as a stage of the process of change, but none are themselves causes. To make this assumption would be to conflate the evidence for an object's existence with the nature of that object (Bolton, 244), or in other words, we assume that since the internal objects of fire appears before combustion, its priority is an essential part of the relation between cause and effect. This is a confusion of the two sources of the content of sensation. We confuse the relations we recognize for the sensations we receive, and thus misunderstand sequence as something essential to the causal relationship, rather than a result of experiencing the world in time.

Using sequence in this way also denies the intentional aspect of sensation. It assumes that what we witness is unaffected by our act of sensation itself, and does not account for the fact that we are not witnessing the external objects themselves, but an internal representation of them. Shepherd finds this to be the source of contention between Berkeley, Hume, Brown and herself. In Shepherd's opinion, because each of these philosophers expresses the synonymity of the two kinds of content, to different degrees and in different forms, each of their theories contain serious consequences for their metaphysics, as we have seen, and for how they find justification for our causal belief. For Hume, the main consequence is a grand skepticism about perception and the world, while for Berkeley it is the difficulty in creating an account of the source of ideas while avoiding solipsism. Brown accounts for how objects relate to one another in space and time, but he does not account for why these relations must be, other than to specify that they are a result of divinely ordained sequence, which gets us no closer to understanding causal relationships, and fails to establish any true metaphysical relation between objects, a consequence which Berkeley must also face. While Brown's sequence 
conveniently accounts for the necessity of sequence, it only tells a partial causal story and relies on the benevolence of God to assure its correctness.

\subsection{Shepherd's Epistemic Justification for Causal Belief}

Shepherd wishes to provide a complete and accurate account of the general causal principles of the universe, in order to avoid the problems that she feels arise from other causal accounts, such as those of Brown, Berkeley, and Hume. Understanding how our faculty of sensation operates is essential to determining how we are able to justify the beliefs we form about the external world and the relationships between the objects which inhabit it. Shepherd sources this justification within the very act of sensation itself as a combination of the sensations we experience and the rational judgements we make. She sees the composite nature of sensation, the merger of aetiological and intentional content, as both the source of and the evidence for our belief in necessary connection. Our ability to perceive and recognize the relationships between objects, internally and externally, is not properly possible without the mind and the reason acting in concert with sense. Either part of sensation alone is not capable of giving us this justification.

Hume and Shepherd alike indicate the problems with trying to justify belief when we make recourse solely to intuition or to reason, or solely to sensation/perception. As epistemologists, Shepherd, Hume, Berkeley, and Brown all believe that our knowledge is experientially based, though they also agree that experience alone is also not enough to justify our belief. Hume believes our justification comes from experience and our imagination recognizing connection through habituation. Brown and Berkeley both believe in a combination of experience, intuition, and faith as justification for our belief. Our ability to trust in experience and the relationships we perceive is an inborn tendency 
given to us by a benevolent God. Where Shepherd stands apart, is in her belief that experience and reason work together to simultaneously grant and justify our causal knowledge. This is not a habitual process like Hume's, but is rather the product of constant cooperation between sense and reason within the grander act of sensation itself. It is worth applying Shepherd's terms to these other philosophies as it will help in determining where the differences between them lay and how she shapes her own theory in response to the difficulties that other interpretations of perception present.

For Hume, the intentional content of perception is imparted to us by the imagination. Through repeated exposure to certain events and sequences thereof, we form a belief about the operations of the world. This does not correspond to any real relations in the world, or if it did we could never know it for certain. Instead we rely on our synthesis of memories to formulate notions of cause, effect, and relations between objects in general.

Brown, in a more traditional sense, holds to an intuitive account of perception. The relation between cause and effect is based on the invariableness of priority of antecedent to subsequent. The aetiological content is the objects of sense which we receive as impressions on the senses, while the intentional content is formed by the mind intuitively recognizing the invariable nature of their ordering as part of the universal regularity, and the power of antecedents to act as cause.

In Brown's case sensation is a passive endeavour, the process itself is a mere bombardment, and it is the mind which then takes the information and has intuitions about it. Hume, in a similar fashion, paints the senses as receptors, although the imagination is much more active than Brown's intuition, which is an instinctive or 
reactive capacity of the mind. Shepherd thus maintains that both men are unable to provide a satisfactory account of sensation, both because they deny the active engagement of our faculty of sensation with the external world, and because their accounts of intentional content are not strong enough to provide "epistemic justification of causal beliefs," (Bolton, 245). Just as the laws of nature and intuitions can be used as proof for and against the truth of causal belief (PWMS 2.222-223), and are thus provide insufficient reason to justify our beliefs, habit is insufficient because it is too focused on sorting out the properties of particular causes and effects. Shepherd explains that Hume makes a mistake when he supposes that it is, "necessary to demonstrate, in every particular instance, what particular Effect must necessarily flow from its object, in order to gain the idea of necessary Connexion. The how and the why have nothing to do with the general reasoning affecting the general proposition," (PWMS 1.59). Likewise, she believes, "it is in vain to say that a habit of association of ideas from observing 'contiguity in time, and place,' between objects is all we know of power; a habit of the mind will not begin existence, will not introduce a quality," (PWMS 1.46) because she believes that habit can only give us information of the particular causes that happened in the past, but this association does not have the strength to account for causal power. Hume admits that sequential accounts of causation are weak, and that our customary beliefs are easily proven false. Brown is adamant that his understanding of cause provides us with absolute evidence that our belief is correct, but as Shepherd points out, intuition can easily be used to both prove and disprove any of our notions and is useless as justification for belief as a result. 
Berkeley's opinion of sensation is a little more difficult to categorise in the same way due to the fact that objects, by his account, are actually ideas. Thus he does not have to account for interactions between the objects of sense and the operations of the mind in the same manner, and with the same urgency, because they are both related to the mental realm and not inherently incompatible as minds and bodies are often considered.

Nevertheless he must still account for the difference between intentional and aetiological content of sensation. The risk, if he doesn't, is that real objects could possibly be considered as the products of our imagination, which means we could create the world to our will, or conversely there is nothing real (idea or otherwise) to which our internal representations give reference, and the benevolence of God and usefulness of creation is called into question. Under Berkeley's account of objects, the aetiological content of our sensation is the ideas which are impressed upon the senses, the source of which is God. The intentional content is our immediate understanding, or intuition of what it means for something to exist as a sensible object. We intuitively realize that as ideas, all objects must exist within a mind, and since our own minds are not always present there must be some Divine perceiver. The beneficence and necessity of God is all the proof that we need to justify that our understanding of the relation between objects is correct.

Unlike Berkeley, Shepherd grants a great power to both human observation and reason. Sensation is an active cognitive process that combines reason, intuition, and imagination with an engaged experience of the internal objects available to us. At the same time she tempers this with her insistence on the existence of external objects, and prevents it from becoming a source of subjectivist skepticism, wherein we doubt everything about the world except for the fact that we have experiences, and eventually 
solipsism, as Berkeley is often accused of only narrowly dodging because of divine intervention. Shepherd explains that "the ideas of colour cannot be imprinted on the eye...for there are no such IDEAS, until after the eye, as an instrument has been affected by some sorts of outward objects," (PWMS 2.199-200). Sensation, as she describes it here, needs an external world for its input, since the ideas of sense are only formed after the sensory organs have received something from the external world. This is a response to Berkeley's notion of sensation, which posits that ideas are impressed upon the senses. Shepherd argues that the "senses" do not deal with "ideas" but with the qualities presented by external objects. She believes that asserting that the senses use what the senses are required to form begs the question of which existed first, the idea or the sense organ (PWMS 2.198-199). While the imagination, memory, and reason are capable of operating without constant physical input, we do not perceive the ideas via the organs of sense; we may perceive some of their sensible qualities in this way, but the actual ideas are relations within these faculties themselves. In the end imagination, memory, and reason are but engines without fuel when an external world is completely lacking. Sensations are the only original content of our knowledge, yet they are not mere impressions, they are the qualities we perceive acting in concert with the ideas of reason in order to create knowledge. The internal objects we perceive give us clues as to the relations between external objects, or causes, and our principles of reason piece together these hints into an accessible account of the external world. ${ }^{22}$

\footnotetext{
${ }^{22}$ In PWMS 2.162-167, Shepherd explains that we can form some knowledge of their natures by subtracting the common element to each, namely the "action of the instruments of sense and the mind". By separating the ideas of sensation in general from those of sensation in particular we can gain a notion of external existences which do not need to be sentient (unlike Berkeley's substance).
} 
The relation between intentional and aetiological content is intimately tied to ideas of necessity, since the presence of aetiological content in sensation necessitates the intentional content which accompanies it. This is the case because sensation is an active capacity. Atherton explains that,

In Shepherd's image, the mind is not a passive reflecting surface, but is able to intuit ${ }^{23}$ its own presence, through its interactions with external objects and hence able to divine the presence of a causal process, even though the exact nature of this process remains hidden.

(Atherton 2005, 83)

If the aetiological content of sensation was unaccompanied by intentional content it would be as though we were perceiving while also being unconscious, which is what Shepherd believes is the conclusion of all passive accounts of sensation.

For Shepherd our justification for belief in causation comes from our very sensations and their relation to the ideas of reason. On our first experience of a new object we find we must account for the objects origin. We are traditionally left with two options, either something external to the object in question is responsible for its existence or the object itself is responsible. But "as every thing not yet in existence, to exist at all, must begin, and as the beginning of any thing must always be supposed, by the nature of the action", nothing can bring itself to be without already being (PWMS 1.37). We come to the conclusion that there must be something external to the new object which is to be held accountable for its existence, and thus they are necessarily connected. Shepherd maintains that, "it is this sort of REASONING UPON EXPERIMENT, which takes place

\footnotetext{
${ }^{23}$ From earlier discussion in this chapter, and that which is to follow when looking at framework models of perception, I find Atherton's understanding of this process as an "intuition" problematic. Although it is an immediate understanding achieved by the cooperation of sense and reason, it is not an intuition in that it either is inbuilt in the senses or reason as ideas, nor is it a priori. The closest sense of the word intuition that could apply is instinct, only in so far as the cooperation between sense and reason is inherent to how we are built as beings. More on this contention will come in the following section.
} 
in every man's mind, concerning every affair in life, which generates the notion of POWER, and necessary Connexion ; and gives birth to the maxim, "a like Cause must produce a like Effect,'(PWMS 1.45). It is only through the necessary relationship formed between aetiological and intentional content of sensation within the understanding that we are even capable of making such judgements. We know that the active nature of sensation requires its aetiological content to be accompanied by the intentional, but this relationship works both ways, much in the way the biconditional relationship between causes and effects is formed. If the intentional content is unaccompanied by the qualities presented by external objects, the mind has nothing on which to form its judgements, and thus no intentional content can be created. Bolton explains that when it comes to justifying causal belief, "although we are unaware of the mental operations from which these perceptions result, they can be expressed by a rudimentary argument. It is not just that we perceive events as having causes, but also that belief in the existence of these causes can be supported by reasoning,"(Bolton 245). Thus our epistemic justification for the belief in cause and effect, and necessary connection, comes directly from our active engagement with the external world; it is a by-product of the very nature of sensation that the general principles of causation and necessary connection are immediately made available to us on our first experience of change. We may not be able to quantify or describe our experience at such a time, for this experience happens long before we have the vocabulary to deal with even simple concepts, but this does not mean that our ideas of causality and necessity are any less true or informative for our continued interaction in the world. 


\subsection{Challenging Framework Models of Perception}

With the division between intentional and aetiological content of perception, it is easy to group Shepherd among the philosophers who propose a framework model for perceptual experience, such as Kant. This is a hasty attribution however, as Shepherd does not agree with this model of sensation, nor does it fit within her metaphysics. She emphases that, "Kant imagines time and space to be only modes of the mind, which is mistaking the causes which determine a mode of the mind with the effect, viz. the mode of the mind," (PWMS 2.59, footnote). Shepherd believes that spatiality and temporality reference actual things instead of simply existing as predetermined ways of experiencing the world, which to her is yet another confusion between cause and effect and the contents of sensation. Even though we perceive internal objects spatially and temporally, this is a characteristic of the aetiological content of experience. Framework models try to categorize this aspect of experience as part of the intentional content of sensation, but this category switch makes it difficult to find justification for belief, in a similar manner to the other theories of sensation we have considered, but has its own unique consequences.

Framework models propose that the intentional content of sensation is the only part which is built into perception; the perceptions themselves are framed by this intentional content as a natural tendency of the mind, it is a frame for experience rather than a shared process. Shepherd argues that both the intentional and aetiological content are built right into the act of sensation, which is to say that the way in which we perceive and the judgements we impose are part of the same act of perception, and are inseparable, both conceptually and physically. They work together as the natural and necessary extension of our process of sensation in order for us to be able to formulate ideas and 
create knowledge. If intentional content were the only content built into perception we would run into the problem discussed earlier where the mind would have ideas of relations without actually having any external content on which to formulate such judgements. Our sensations, because of the necessary cooperation between content, are sufficient evidence for belief in an external world. Shepherd, in response to such theories, explains that,

Now, that our living conscious sensations, that is, those consciousnesses which are sufficiently vivid to form strong impressions; and long enough in duration to admit of being compared together ; with the results of their comparisons as again forming a new class of sensations, (ideas of reason,) are the only original, and immediate materials of our knowledge, is the chief feature of the philosophy I would profess. And I do consider these materials as sufficient for every useful opinion ; for the proof of every existence which others refer to "instincts," "primary laws of belief," "ultimate facts," "immediate knowledge by the senses," or other means, which do truly leave the objects of which they testify wholly without any proof whatever ; for, "that we are incapable of thinking otherwise than we do" can itself be no reason that we think rightly.

(PWMS 2.222-223)

She is arguing here that sensations as composed of impressions and the ideas of their relation are the original content of our perception, but this "being built into sensation" which is characteristic of aetiological and intentional content is not the same sort of furnishing of the mind we see in intuitive accounts or framework models. It is a result of the nature of the tool of sensation, much in the same way that the eye is built to see light, but the eye cannot be said to intuit light. Shepherd believes that intuitions or instincts are insufficient explanations for how and why we perceive what we do. Some frameworks for experience can be classed among instincts because they represent an inborn tendency to perceive the world in a certain way. But as Shepherd argues instincts, laws of belief, and immediate knowledge of sensation can equally get us to knowledge of an 
independent and external world, just as they are used as 'undeniable' proof against such existences (PWMS 2.222-223).

In addition to this ambiguity of application, frameworks shift part of what Shepherd considers as the aetiological content of sensation into the intentional category. That we perceive objects in space and time is a mode of perceiving for Kant, but for Shepherd, space and time, like all of our experiences of qualities, are internal representations of actually existing things. The intentional content of sensation consists solely of our ability to recognize the relations between objects. Since the aetiological content can be considered as the qualities which are in the external object itself, the intentional content can be considered as inseparable from the object, that is, "the knowledge of their existence is in and with themselves, as well as of the existences contained in their relations" (PWMS 2.223) and therefore the ideas of reason, of the relations between objects have the same certainty as sensations. This is possible, and necessary, as a result of the fact that these sensations are the only original content of our knowledge. There is no pre-established framework for understanding that is not inherent in the understanding itself and yet separate from sensation. As a result,

The ideas of reason must be the corollaries included in the impressions of sense, from whatever source they may be supposed to arise ; they must be the conclusions of the judgement when the faculties are in a state to exert their power. For independant existences are, by the very terms, and supposition of the statement, unconscious ; and, therefore, must be known of as a result derived from the comparison and included in the relation of those which are conscious.

(PWMS 2.224)

Contrary to the idea that the mind is pre-furnished with ideas or modes which allow sensation to be transformed into ideas, Shepherd believes that the mind's original content can only ever be the ideas of sense, which includes as a necessary 'corollary' the ideas of 
the relations that exist between sensations. Again, this is an unavoidable consequence of the active process of sensation which includes both aetiological and intentional content.

Bolton believes that this version of sensation arises as a direct consequence of the synchronous relationship Shepherd proposes between cause and effect. Bolton explains that,

[Shepherd] maintains, we perceive events as having contemporaneous causes. Intentional content to that effect is built into sensory perception... as she sees it, sense perception involves sensations which are subsumed under ideas of certain relations by latent operations of reason. The relations are 'true' in that, by and large, sensations actually stand in these relations.

(Bolton, 245)

What Bolton is hinting at is that Shepherd's belief that sensation is an active faculty represents or implies an actual merger between the intentional and aetiological content of sensation, not just a conceptual cooperation of two metaphysically or physically distinct processes. Unlike framework models, there is no real distinction between the modes of thinking and the content of experience, much like there is no real distinction between cause and effect in the moment of change. They express one and the same essence because the aetiological roots of our beliefs of causation are in Shepherd's mind, those same very real unknown objects in nature, which are the source of perceptible qualities, and the intentional content is the relationships that the faculty of sensation immediately recognizes and organises its content under. Framework models leave gaps in our reconciliation of internal/external interaction within sensation. On the one hand, if space and time are something which we provide to sensation, it could mean that external objects do not relate to each other in actual space and time, a possibility which is impossible under Shepherd's metaphysics. While Kant might be content to claim that this is plausible (this is still a matter of debate), simply because we can know nothing about 
things-in-themselves, Shepherd believes that to exist is to exist in a certain place and in a certain time. On the other hand, proposing that some of the content of our experience is built into the mind creates the problem of aspects of experience which do not give reference to external objects. Beyond losing the relation of a shared space and time, it means that we are forced into a position where we must question whether any of the relations whatsoever that we recognize in sensation have any external truth. So, while it may seem possible, on one level, to categorize Shepherd's theory of sensation as a framework model of perception on account of its highly subjective nature and the "inbuilt" nature of the contents of sensation, it is incorrect to do so because of the link between frameworks and intuition, as well as the problem it presents for active engagement with an external world.

\subsection{The Value of a Practical Theory of Sensation}

Shepherd's proposal that the justification for the beliefs we form about the external world is built right into our very experience of it is ingenious. As a self contained system, the active faculty of sensation, as she presents it, is built not simply to sense qualities in the world about us, but also to recognize the relationships between said qualities. This is a unique way of answering the question of how minds are capable of interacting with the physical world. If built in this way, sensation is the medium of interaction between the mental and physical world, and we are not required to find some alternative metaphysical or epistemological principle which explains this interaction. The cooperative approach that this represents is promising. It allows us to account for experience and belief on a simple level (conceptually it requires a great deal of work to suss out the specific principles and definitions, as we have seen, but on a practical level it 
presents an efficient way to account for and justify belief through a single process). This lends a great deal of credibility to Shepherd's theory, as I believe it is not the conceptual complexity which marks the quality of a theory of epistemology, but the ease with which it can be used to explain our experience and provide justification for whatever beliefs we arrive at through that experience. The complex appearance of Shepherd's epistemological discussion is a result of the work she was required to do in order to challenge other common notions of perception and sensation before being able to set up her own. Like the development of her metaphysical theory, there are many strong and entrenched ideas about sensation and knowledge formation which need to be addressed before new ones can be proposed. The efficiency with which she answers how and why we come to believe what we do about causation and that we are justified in this belief is what I believe marks Shepherd's theory as a strong contender within the epistemological and metaphysical debates of the Scottish Enlightenment.

Hand in hand with her re-envisioned metaphysics of necessity, Shepherd's epistemological principles provide an interesting and valuable foil to the theories of causality that dominated the Early Modern period. Inevitably each of the principles covered here have only been treated briefly and are deserving of greater individual attention. Likewise there are many other topics which Shepherd covers in her publications that will prove to be goldmines of future inquiry, such as her response to Hume's discussion of miracles, and her own arguments about the nature of God. It is my hope to have shown here some of the complexity and innovation present in her work, and that, as a result, people will be compelled to examine her theories of metaphysics, causality, and epistemology in greater detail in the future. 


\section{Appendices}

\section{Appendix A}

Additional Bibliographical and Biographical Resources

Blakey, R. (1850). A History of the Philosophy of the Mind: embracing all writers on mental science from the earliest period to the present time, (Vol.9).

Brandreth, M.E. Family and Friendly Recollections (1884-5)

Coleridge, S.T. Notebook “Q”, 1833, fol. 73

Letters to Charles Babbage, British Library, London, Add. MSS 37183, 37201

Perkins, M.A (2004). Shepherd , Lady Mary (1777-1847). Oxford Dictionary of National Biography, (Jan 2008). Oxford University Press. Retrieved from http://www.oxforddnb.com/view/article/58699

Shepherd, M. (June 1828). On the cause and effect of single and erect vision. The Philosophical Magazine, 3(18), 406-416. 


\section{Bibliography}

Atherton, M. (Ed.). (1994). Lady Mary Shepherd. Women philosophers in the early modern period. (pp. 147-159). Indianapolis, IN: Hakett.

Atherton, M. (1996). Lady Mary Shepherd's case against George Berkeley. British Journal for the History of Philosophy, 4(2), 347-366.

Atherton, M. (2005, Fall). Reading Lady Mary Shepherd. The Harvard Review of Philosophy, 13(2), 73-85.

Berkeley, G. (1999). Principles of Human Knowledge Three Dialogues. Howard Robinson (Ed.). New York: Oxford University Press.

Bolton, M.B (2011). Causality and causal induction: the necessitarian theory of Lady Mary Shepherd, in Keith Allen and Tom Stoneham (Eds), Causality and Causal Identity. New York, NY: Routledge, pp. 242-261.

Brown, T. (1851). Lectures on The Philosophy of the Human Mind (19th ed.). London: Longman \& Co.

Brown, T. (2010). Selected Philosophical Writings. Thomas Dixon (Ed.). Exeter, UK: Imprint Academic.

Hume, D. (1928). A treatise of human nature.(Book 1). L.A Selby-Bigge (Ed.). Oxford: Clarendon Press.

Hume, D. (1998). An enquiry concerning human understanding. Anthony Flew (Ed.) Chicago, Il: Open Court.

Locke, J. (1965). An Essay Concerning Human Understanding (revised ed.). John W. Yolton (Ed.). London: Dent. 
Malebranche, N. (1997a). Dialogues on Metaphysics and on Religion. Nicholas Jolley and David Scott (Eds.). Cambridge: Cambridge University Press.

Malebranche, N. (1997b). The Search after Truth. Thomas M. Lennon and Paul J. Olscamp (Eds.). Cambridge: Cambridge University Press.

Shepherd, M. (2000). The Philosophical Works of Lady Mary Shepherd. (Vol. 1-2). Jennifer McRobert (Ed.) Sterling, VA: Thoemmes Press. 